\title{
Marine fish spermatozoa: racing ephemeral swimmers
}

\author{
Jacky Cosson, Anne-Laure Groison ${ }^{1}$, Marc Suquet $^{2}$, Christian Fauvel $^{3}$, Catherine Dreanno ${ }^{4}$ \\ and Roland Billard ${ }^{5}$
}

CNRS, Univ. of Paris VI, P\&M Curie, UMR 7009, Marine Station, 06230 Villefranche sur mer, France, ${ }^{1}$ Biology Department, University of Bergen, Thormøhlensgate 55, Bergen 5020, Norway, ${ }^{\prime}$ Ifremer, ARN, 29840 Argenton, France, ${ }^{3}$ Ifremer, LALR, 34250 Palavas, France, ${ }^{4}$ CNRS, UMR 7144, Marine Station, Place Georges Teissier, BP 74, 29682 Roscoff, France and ${ }^{5}$ Laboratory of Ichthyology, National Museum Natural History, Rue Cuvier, 75231 Paris, France

Correspondence should be addressed to J Cosson; Email: cosson@obs-vlfr.fr

\begin{abstract}
After a long period of spermatogenesis (several weeks to months), marine fish spermatozoa are delivered at male spawning in seawater (SW) at the same time as ova. In some fish species, as the ova micropyle closes quickly after release, these minute unicells, the spermatozoa, have to accomplish their task of reaching the micropyle within a very brief period (several seconds to minutes), for delivery of the haploid male genetic information to the ova. To achieve this goal, their high-performance motile equipment, the flagellum, must fully activate immediately on contact with the SW and then propel the sperm cell at an unusually high initial velocity. The cost of such 'hyperactivity' is a very rapid consumption of intracellular ATP that outstrips the supply. The spermatozoa become rapidly exhausted because mitochondria cannot compensate for this very fast flagellar energy consumption. Therefore, any spermatozoon ends up with two possibilities: either becoming exhausted and immotile or reaching the egg micropyle within its very short period of forward motility (in the range of tens of seconds) before micropyle closure in relation to both contact of SW and cortical reaction. The aim of the present review is to present step by step the successive events occurring in marine fish spermatozoa from activation until their full arrest of motility. The present knowledge of activation mechanisms is summarized, as well as a description of the motility parameters characterizing the motility period. As a complement, in vitro results on axonemal motility obtained after demembranation of flagella bring further understanding. The description of the sperm energetic content (ATP and other high energy compounds) and its evolution during the swimming period is also discussed. A general model aiming to explain all the successive cellular events occurring immediately after the activation is presented. This model is proposed as a guideline for understanding the events governing the sperm lifespan in the marine fish species that reproduce through external fertilization.

Reproduction (2008) 136 277-294
\end{abstract}

\section{Introduction}

Marine fish spermatozoa are flagellated unicells, which have to deal with an extremely hostile environment upon delivery in seawater (SW). During whole spermatogenesis, they have a safe environment, both surrounded and nourished by Sertoli cells and endocrine cells (Leydig cells) combined with non-harmful fluid (seminal plasma). During spermatogenesis, sperm cells are prepared for accomplishing their fertilizing task for which they need to fully exploit their swimming ability immediately and as fast as possible in order to encounter the egg.

Most knowledge on sperm movement developed by simple flagella comes from studies on the classical model of sea urchin spermatozoa (Gibbons 1981) and on mammals for more structurally complex sperm cells. Nevertheless, some characteristics of fish sperm show original features: motility duration (Billard 1978, Billard \& Cosson 1988, 1992), motility initiation (Morisawa 1985,
1994, Cosson et al. 1995a), or motility pattern (Boitono \& Omoto 1992, Cosson et al. 1997). Most studies were carried out in fresh water fish species; there is less information concerning marine sperm characteristics. In the latter, motility activation occurs immediately after contact with SW, a high osmolarity medium compared with seminal fluid (SF). The initial velocity is very high at activation, but motility duration lasts for periods ranging only $40 \mathrm{~s}$ to $20 \mathrm{~min}$ as an energetic consequence of the high velocity.

Marine fish spermatozoa present unique features with which to study the specific aspects of sperm movement: (1) Brood fish are easily available for a part of the year in farmed species. (2) Fish sperm is easy to collect and save for short periods; marine fish sperm are easy to cryopreserve. (3) Sperm of fishes with external fertilization is immotile in the $\mathrm{SF}$, and transfer to a swimming competent medium fully triggers motility, scores of which are presently used for selection of males, or for evaluation of cryopreservation results. A correlation between sperm motility and ability to 
fertilize the eggs has been established in many marine fish species. (4) Fish sperm cells are homogenous; all spermatozoa can be activated at the same time and then swim with very similar characteristics at a certain time point post-activation, an advantage for biochemists. (5) In many fish species, the flagellum is 50-60 $\mu \mathrm{m}$ long with a ribbon shape (presence of fins) instead of cylindrical; thus, the flagellum appears brighter by dark-field microscopy, allowing clear visualization of wave shapes. Attenuation (so-called dampening) of waves gradually invades the whole length of the flagellum during motility. At the last period before full stop, the waves are restricted to one-third of the flagellum combined with a drastic decrease of flagellar beat frequency (BF) leading to a decrease in translation efficiency (Cosson et al. 1997). (6) In several fish species, spermatozoa follow linear tracks; the flagellar bending is symmetrical, probably because of the absence of $\mathrm{Ca}^{2+}$ sensitivity of the axoneme.

Despite all these original features, few detailed studies on marine fish spermatozoa flagellar motility behavior have been conducted. In the present paper, we aim to gather the present knowledge on sperm movement characteristics of marine fish, with special emphasis on their high velocity capacities. A relationship between ionic effects, osmolality, and transience/abortion of motility is established. Using this indicator of the local and temporal ionic concentrations, we propose a model in which, following a transfer from SF to SW, the extracellular osmolality makes the intracellular ionic concentration of sperm evolve rapidly during the course of the motility phase; as a consequence the flagellar axoneme immediately activates but becomes gradually exposed to an increasing intracellular ionic environment preventing the development of distal waves and further leading to their full arrest. For general information on fish sperm, the reader is advised to consult the following review papers (Stoss 1983, Billard et al. 1994, 1995, Inaba 2003, Alavi \& Cosson 2005, 2006, Lahnsteiner \& Patzner 2007) and a book, Fish Spermatology (Alavi et al. 2007).

\section{The SF osmolality prevents sperm motility in the genital tract}

Spermatozoa of marine fishes reproducing by external fertilization are delivered in SW at spawning. Obviously, these individual unicells have to cope immediately with SW (a medium external to the wheedling fish fluid) that is very harmful due to its high ionic concentration constituting a high osmolarity medium compared with the sperm cytoplasm.

In marine fish, the SF osmolality is much lower than that of SW and low enough to prevent motility (Table 1). In addition, the sperm cells concentration in the semen is usually high (see Table 1) which thus contributes to sperm immotility by local exhaustion of $\mathrm{O}_{2}$ and generation of high $\mathrm{CO}_{2}$ concentration in milt. In some species, spermatozoa have the ability to swim in seminal SF, sometimes only transiently. Motility also occurs when SF is slightly diluted with SW, which may accidentally happen at sperm collection. In turbot sperm, a 10\% dilution of $\mathrm{SF}$ is enough to allow full motility. Contamination by urine may also accidentally happen when collecting sperm (Perchec et al. 1995a, 1995b, Perchec-Poupard et al. 1998): in turbot (Dreanno et al. 1998), such urine contamination leads to deleterious effects to spermatozoa.

The ability of spermatozoa to swim is eventually dependent on their maturation in the ducts, prior to ejaculation. This maturation is frequently controlled in a hormonal manner and by adjustment of ionic concentration in the SF; such maturation can be induced in vitro (Redondo-Muller et al. 1991). This sperm maturation process studied in turbot ( $M$ Suquet, unpublished observations) and in sea bass (Dreanno et al. 1999a) is not dependent on the internal ATP stores.

The sperm immotility in SF suffers a few exceptions: in sharks (dogfish, Triakis scyllia), spermatozoa are immotile in the testis but become progressively motile in the spermiduct during their descent in the epididymal duct; nevertheless ejaculated sperm are immotile while motility is fully triggered only at contact with SW (Minamikawa \& Morisawa 1996).

Table 1 Sperm density, $\mathrm{pH}$, and osmolality of seminal fluid (SF) in several marine fish species.

\begin{tabular}{|c|c|c|c|c|}
\hline Species & Sperm density $\left(10^{9} / \mathrm{ml}\right)$ & $\mathrm{pH}$ & Osmolality (mOsmol/l) & References \\
\hline Turbot & $2-9$ & ND & ND & Chauvaud et al. (1995) and Suquet et al. (1997) \\
\hline Turbot & ND & $6.65-7.0$ & ND & Suquet et al. (1994) and Dreanno et al. (1998) \\
\hline $\begin{array}{l}\text { Tuna testicular } \\
\text { sperm }\end{array}$ & $30-50$ & ND & ND & Doi et al. (1982) and Mylonas et al. (2007) \\
\hline Halibut & $>100$ & ND & ND & Cosson et al. (2008b) \\
\hline Sea bass & 60 & ND & 317 & Dreanno et al. $(1998,1999 b)$ and Fauvel et al. (1999) \\
\hline Sea bass & $10-40$ & ND & 400 & Villani \& Catena (1991) \\
\hline Hake & $8.3 \pm 3$ & ND & ND & Cosson et al. (2008b) \\
\hline Cod & $4.5-8.7$ & $7.9-8.4$ & $\begin{array}{l}360-380 \\
400-417\end{array}$ & Hwang \& Idler (1969) and Litvak \& Trippel (1998) \\
\hline Sea bream & ND & 7.8 & 365 & Chambeyron \& Zohar (1990) \\
\hline $\begin{array}{l}\text { Tilapia (raised in } \\
\text { seawater) }\end{array}$ & & & 351 & Linhart et al. (1999) \\
\hline Petromyzon marinus & & & 250 & Ciereszko (2008) \\
\hline
\end{tabular}

ND, not determined. 


\section{Transfer from SF into SW triggers full motility}

Hypertonicity induces the motility of spermatozoa in marine teleosts: in cod, Gadus morhua macrocephalus (Westin \& Nissling 1991); in flounders, Limanda yokohamae and Kareius bicoloratus (Morisawa \& Suzuki 1980); in sea bass, Dicentrarchus labrax; in sea bream, Sparus auratus (Billard 1978); in gray mullet, Mugil cephalus, Trachurus mediterraneus, Mullus barbutus, Boops boops, and Diplodus sargus (Lahnsteiner \& Patzner 1998); and in goby, Gillichthys mirabilis (Weisel 1948). Demonstration that osmolality is a key factor for motility activation comes from experiments using hypertonic sugar solutions ( $1 \mathrm{M}$ and without any ions) instead of SW as triggering solution: this is shown in halibut (Billard et al. 1993), turbot (Chauvaud et al. 1995), sea bass (Dreanno et al. 1999b), tuna (Cosson et al. 2008b), cod and hake (Cosson et al. 2008a), sea bream (Cosson et al. 2008b) and mullet (Lee et al. 1992). When $\mathrm{Na}^{+}$ions of SW are substituted by choline (choline chloride $0.5 \mathrm{M}$ ), motility activates as well (Cosson et al. 2008b). Experimental conditions can visually demonstrate that the SW activation process is fully and immediately reversible. Native turbot spermatozoa briefly exposed to conditions where no motility is possible (fourfold diluted SW, immobilization medium (IM), or media below $300 \mathrm{mOsm} / \mathrm{kg}$ ) are able to immediately initiate full motility upon transfer to a swimming medium (SM), i.e., SW. At transfer of the same sperm cells from SM back to IM, motility fully stops within a fraction of second.

Tolerance of motility toward osmolality depends on species: motility is initiated at osmolality (in mOsm/l) of 300 or above in turbot (Chauvaud et al. 1995, Dreanno et al. 1999C); 400 in sea bass (Villani \& Catena 1991, Dreanno et al. 1999b); and 333-645 in tilapia, Sarotherodon melanotheron (Linhart et al. 1999) but, according to recent results (Legendre et al. 2008), 300-970 for fishes reared in SW (450-1600 for fishes reared in twice the salinity of SW), and 480 in Atlantic croaker (Vizziano et al. 1995). In halibut, $\mathrm{NaCl}$ solutions with osmolalities 350-1200 mOsm/l also permit motility (Billard et al. 1993). At $300 \mathrm{mOsm} / \mathrm{l}$, a lower percentage of turbot spermatozoa are activated (70\% compared with $90 \%$ in control at $1100 \mathrm{mOsm} / \mathrm{l}$ ) but the velocity is same as in control. In sea bass, activation also occurs at osmolality lower than SW; at $630 \mathrm{mOsm} / \mathrm{l}$, there is no change of initial velocity but at $40 \mathrm{~s}$, flagella produce only oscillations without resulting in any efficient forward displacement. SF separated from turbot milt $(316 \pm 1.5 \mathrm{mOsm} / \mathrm{l})$ is permissive to motility in many samples, but $\mathrm{CO}_{2}$ concentration is the main factor preventing motility in $\mathrm{SF}$ with total $\mathrm{CO}_{2}$ concentration of $8.97 \pm 1.53 \mathrm{mmol} / \mathrm{l}$ or $8.66 \pm 1.48 \mathrm{meq} / \mathrm{l} \mathrm{HCO} 3$ (at a $\mathrm{pH}$ of $7.58 \pm 0.03$ ), $\mathrm{pCO}_{2}$ being $6.74 \pm 1.15$ (Dreanno 1998).

In sea bass, solutions of 150-300 mOsm/l reversibly prevent motility but full activation occurs at $1100 \mathrm{mOsm} / \mathrm{l}$
(Fauvel et al. 1998, Dreanno et al. 1999b). In cod, sperm motility does not activate in a twofold dilution of SW by fresh water; therefore, this solution can be used as a short-term diluent. The motility is activated by transfer in artificial SW solutions with osmolalities from 700 to $1550 \mathrm{mOsm} / \mathrm{l}$. Sperm is not active in SF but when the SF is diluted 1:4 by SW, full flagellar activation occurs (Cosson et al. 2008b). In hake, a diluent made of SW:DW in a 1:4 ratio does not activate motility, but allows further full activation by undiluted SW (Cosson et al. 2008a).

A general rule for sperm of marine species is that the osmolality gradient must be positive between outside and inside sperm cells to trigger motility. Although a brief and transient activation is observed, when the amplitude of the difference of osmotic pressure (OP) is too low; it consists of stochastic initiation of a few flagellar waves during brief time period (about $1 \mathrm{~s}$ ) in any individual spermatozoon intercalated with very long resting periods. Similar process probably exists in cases where semen is contaminated by low quantities of SW; motility is transiently but not fully activated, therefore such sperm do not exhaust their ATP content as discussed later in detail in this review. Such transient activation already demonstrates the reversibility of the activation process but this reversibility can also be appreciated in the more direct experiments that follow (Cosson et al. 2008b). Sperm cells were diluted in an immobilizing solution and injected through a tiny micropipette $(20 \mu \mathrm{m}$ diameter and connected to a syringe providing low pressure) into a $100 \mu \mathrm{l}$ drop of SW settled in between glass slide and cover slip. By observation with a microscope focused on the boundary between the SW and the injected immobilization solution (IS), each individual spermatozoon can be seen alternatively active or inactive depending, whether it is in contact with SW or IS respectively. This shows that activation and inactivation periods follow each other, which demonstrates both full reversibility and immediacy of the triggering/inactivating mechanism. Using a similar experimental design (Fig. 1), one can deliver a gentle but local flow of SW through a tiny micropipette $(2 \mu \mathrm{m}$ opening) to any portion of the flagellar length of a sperm cell, the latter being stuck by its head to a second holder micropipette (3-4 $\mu \mathrm{m}$ opening) itself immersed in a drop of IS. This way, local activation and inactivation can be visualized successively at any site located along the flagellum.

Nevertheless, the general model based on osmolality control of marine fish sperm motility activation has exceptions. Combined with osmolality, some species with external fertilization control sperm motility by $\mathrm{CO}_{2}$ via carbonic anhydrase (Inaba et al. 2003) as observed in many flatfish species. Other species, like herring, control sperm motility through contact with some sperm initiation factor secreted by the egg of the same species. Both examples are further detailed in this review. 

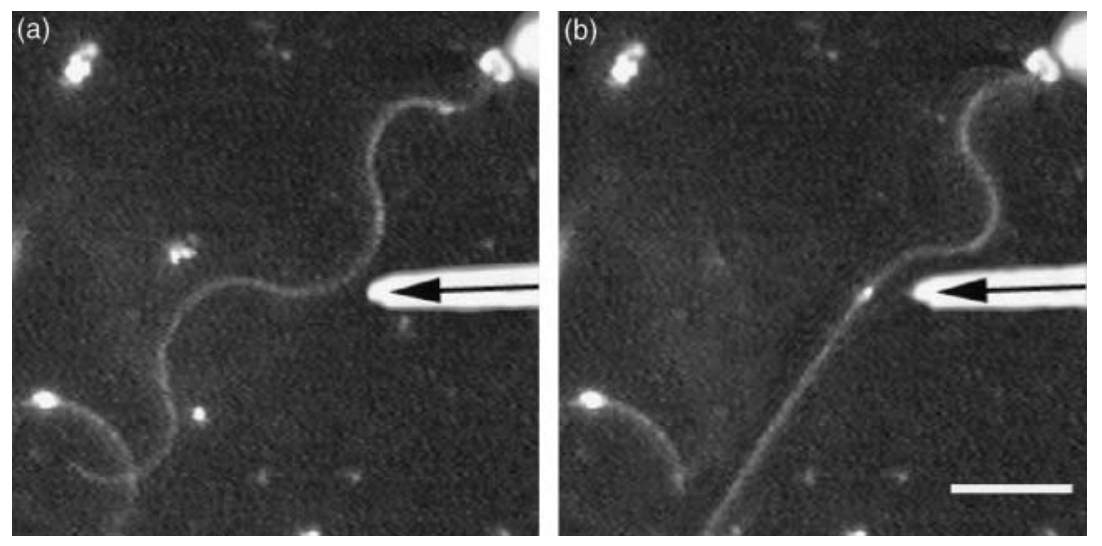

Figure 1 Motility control of flagellar waves by local delivery of low-osmolality medium. (a) A turbot spermatozoon is clamped to a holding micropipette (upper right corner) and propagates waves in SW. (b) A second micropipette (on right, with arrow inside) is approached to the middle part of the beating flagellum, a pulse of non-swimming solution locally delivered have stopped the tipward progression of waves. Scale bar corresponds to $10 \mu \mathrm{m}$.

An ambiguity is encountered in the case of the sperm of the wolffish (Anarhichas lupus), which is motile on stripping and remains as such for several days; motility is restricted to a $200-500 \mathrm{mOsm} / \mathrm{l}$ osmolality range. It has been suggested that motility is adapted to the local environment of the egg, which in this species presents osmolality lower than the surrounding SW (Kime \& Tveiten 2002) which could be related to the fact that fertilization seems to be close to 'internal' in this species (Pavlov 1994, Pavlov et al. 1997).

Concerning $\mathrm{pH}$, it is of low influence on motility and therefore $\mathrm{pH}$ is considered as a critical factor controlling motility. Values of $\mathrm{pH}$ in SF of several species are presented in Table 1.

\section{Immediately after activation, marine fish sperm swim with very high efficiency}

For any spermatologist observing marine spermatozoa through a microscope right after activation by SW, it is striking that by any appreciation parameter (even just 'visually') all spermatozoa appear very 'fast' swimmers. This impression is confirmed by many quantitative assessments of motility parameters (Cosson 2007a). Experimental values of the initial sperm speed of forward displacement in various species confirm a high velocity (expressed in $\mu \mathrm{m} / \mathrm{s}$ ): $150-180$ in halibut (Billard et al. 1993, Vermeirssen et al. 2004), 160 in fugu (Takai \& Morisawa 1995), 130 (Cosson et al. 2008a) or 65-100 (Trippel \& Morgan 1994) in cod, 130 in hake (Cosson et al. 2008a, Groison et al. 2008), 215-230 in tuna (Cosson et al. 2008b), 220 in turbot (Cosson et al. 1997, Dreanno et al. 1999c), and 120 (straight line velocity) in sea bass (Dreanno et al. 1999a, 1999b), similar to values published by Abascal et al. (2007). However, these velocity characteristics may be modulated by sperm microenvironment and particularly $\mathrm{pH}$ and osmolality of the SM. Some discrepancies (as observed for cod sperm) probably come from the temperature at which measurements were obtained (Alavi \& Cosson 2005), $22{ }^{\circ} \mathrm{C}$ in the case of Cosson et al. (2008a) compared with $2{ }^{\circ} \mathrm{C}$ in the case of Trippel \& Morgan (1994). Biophysical prediction is that the velocity value is more than doubled when the temperature is raised by $10^{\circ} \mathrm{C}$.

These high velocity values are a consequence of the high flagellar BF ranging $50-70 \mathrm{~Hz}$ depending on species. Such high BF values are reminiscent of the so-called 'hyperactivation' process occurring to mammalian spermatozoa in the vicinity of ova, which consists of change in activity. However, in the case of fish, spermatozoa present much less chaotic movement characteristics, i.e. much more propulsive in a straightforward manner, probably corresponding to a different need and function.

\section{The motility period is limited to minute range duration for marine fish's sperm}

Sperm motility has a longer duration for marine fishes compared with fresh water species. This is mostly related to osmotic shock leading to membrane damage. The total duration of flagellar activity, including progressive and non-progressive forward motility is quite short, ranging from minutes to tens of minutes, which is very low compared with mammalian sperm or invertebrate spermatozoa (sea urchin or oyster sperm), which can swim for several hours.

The total duration of motility can be estimated either by visual microscopic observation of movement until full cessation of activity or by extrapolation to zero of the curve representing the percentage of motility versus time obtained by Computer Assisted Sperm Analysis (CASA; Cosson 2007a). The latter estimation is easiest in case of a linear decrease but more difficult in case of exponential or sigmoidal decrease. Table 2 gives values for the two types of estimation. In contrast to the motility durations described in Table 2, eel spermatozoa can swim for more than 20 min with little change in their motility characteristics (Gibbons et al. 1985). The same is true in conger spermatozoa (Cosson et al. 2008b). 
Table 2 Sperm motility duration in seawater of various marine fishes.

\begin{tabular}{lll}
\hline Species & $\begin{array}{l}\text { Full } \\
\text { immotility (s) }\end{array}$ & Extrapolation (s) \\
\hline Halibut (Billard et al. 1993) & $110-120$ & 100 \\
Turbot (Dreanno et al. 1999C) & 600 & $6-800$ \\
Sea bass (Dreanno et al. 1999b) & $50-60$ & 60 \\
Cod (Cosson et al. 2008a) & $7-800$ & 600 \\
Hake (Cosson et al. 2008a) & $4-500$ & 350 \\
Tuna (Cosson et al. 2008b) & 140 & 125 \\
\hline
\end{tabular}

Full immotility refers to the time period at which no single sperm is seen active. Extrapolation means the intersection of the percent motility curve with the time abscissa.

It has been demonstrated that the duration of motility is temperature dependent and species specific, varying from $\sim 1 \mathrm{~min}$ for L. yokohamae and L. herzensteini, 2 min for Verasper moseri, 5 min for Pecten maximus, and 7-10 min for Vaejovis variegatus, to an hour in cod (Trippel \& Morgan 1994) at $2{ }^{\circ} \mathrm{C}$ in the latter case. In hagfish, it was observed that sperm motility can last for periods up to $10 \mathrm{~min}$ (Morisawa 1995).

Motility duration is also limited by damage that appears during the motility period. This damage appears in SW during the motility phase; it can be observed at high microscopical magnification. Either cytoplasmic blebs emerge anywhere along flagellar length, eventually impairing the propagation of waves ( $f$ to $i$ in Fig. 2a) or a curling process (i in Fig. 2a) may develop at the flagellar tip, which obviously shortens the efficient part for wave propagation along the flagellum. Such curling is reminiscent of the naturally occurring curling (helicoidal) observed in intact eel flagella (Gibbons et al. 1985). Such blebs or curling damages usually result from local membrane defects engendered by osmotic stress and they are usually reversible by reversing the osmolality of the surrounding solution to correct the values (Perchec et al. 1996). Such damages may occur when milt happens to be contaminated by urine at collection by stripping (Dreanno et al. 1998, Perchec et al. 1998).

\section{Most motility parameters decrease during the motility period}

Several methods to measure motility parameters have been recently described, some of which, known as CASA, enable automatic and statistical analyses (Cosson 2007a). Most of the parameters used to characterize motility decline within tens of seconds to few minutes depending on species and this general decrease leads to eventual full arrest of spermatozoa (Cosson et al. 1997, 1999). When plotted as a function of time, the percentage of motile cells, the BF, and the velocity show differences between species in the time scale but a general tendency is exhibited in all cases, that is, a high initial value followed by a decline during the motility period.
A
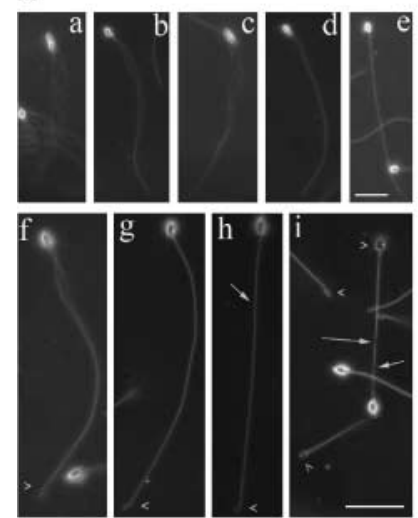

C

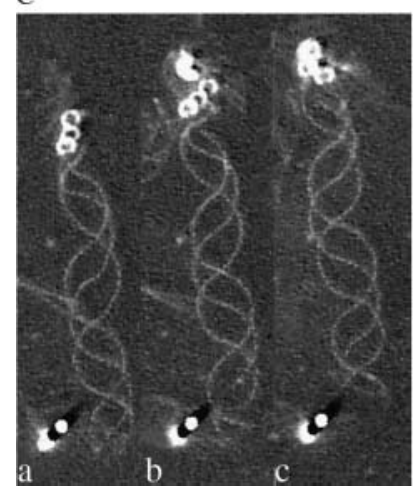

B
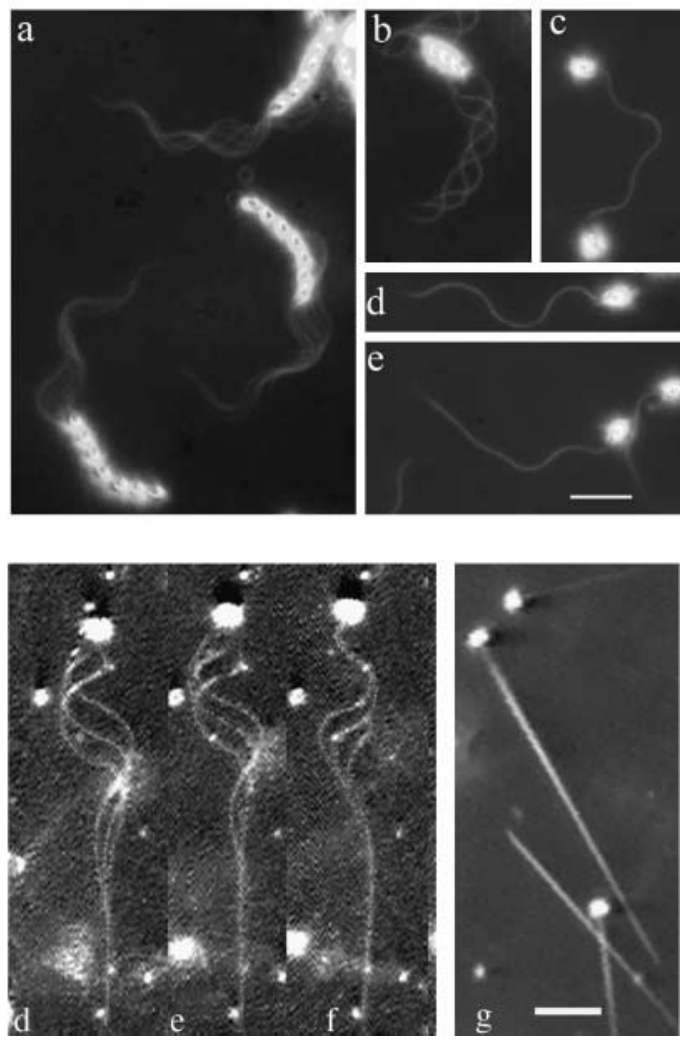

Figure 2 Photographs of moving spermatozoa of (A) cod, (B) tuna, and (C) turbot. Photographs were obtained using dark-field microscopy and stroboscopic illumination. (A) Flashes every $3 \mathrm{~ms}$ (three flashes per video image) head and flagellum appear in three successive positions. Cod sperm in which motility was initiated by transfer to seawater (a) since $14 \mathrm{~s}$ (waves propagating in the whole length of the flagellum); (b) at $36 \mathrm{~s}$ and (c) $58 \mathrm{~s}$ (waves propagating in the three-fourth of the flagellar length); (d) at 2 min (low-amplitude waves only in the vicinity of the head); (e) at $3 \mathrm{~min}$ (full stop). ( $\mathrm{f}-\mathrm{i})$ Damage provoked by SW on cod spermatozoa: appearance of blebs (arrows) and curling of flagellar tip (arrow heads). Scale bar: $10 \mu \mathrm{m}$. (B) Swimming tuna spermatozoa spermatozoa: (a) seven flashes applied during the $50 \mathrm{~ms}$ exposure, (b) three flashes allowing visualization of wave propagation from base to tip, (c) single flash showing flagellum in asymmetric shape, (d) same but symmetric shape, and (e) wave dampening. Scale bar: $10 \mu \mathrm{m}$. (C) Swimming turbot sperm at high magnification in $(\mathrm{a}-\mathrm{C})$ three successive video images (three flashes per image) of a spermatozoon activated since $23 \mathrm{~s}$, (d-f) same at $63 \mathrm{~s}$ with the dampening of the waves appearing progressively during the motility period leading to full stop, and (g) at $3 \mathrm{~min}$. Scale bar: $10 \mu \mathrm{m}$. 
Additional methods, designed to describe the details of wave parameters, were initially developed to study the sperm flagella of invertebrates (Brokaw 2004) and were adapted to marine fish spermatozoa (Cosson 2004, 2007a). In sperm cells from marine fishes, the initiation of the flagella waves occurs just at the junction between head and tail, therefore wave propagation occurs from head to flagellar tip, leading to opposite forward movement of the spermatozoon, head first (Cosson $2007 b$ ). The wave's velocity along the flagellum ranges from two to three times the translational velocity of the spermatozoon itself.

\section{Wave shape changes during the motility period}

In fish spermatozoa, the wave shape is of the 'arc sine' type, i.e., linear segments intercalated between two curvatures, similar to what occurs in tunicate sperm flagella (Brokaw 1991b) or sea urchin. At initiation of motility, several successive waves occupy the whole flagellar length. The wave shape results partly from the physical constraints imposed by the external milieu and can be affected by one important physical parameter, the viscosity: this is observed when methyl cellulose (MeCell; Brokaw 1966), a high molecular weight polysaccharide (non-permeant through membranes) is included in the SM, SW in this case. When MeCell is included at $0.4-1 \%(\mathrm{w} / \mathrm{v})$, viscosity increases from 10.86 (pure SW) to 76.3 centipoise ( $1 \% \mathrm{w} / \mathrm{v}$ MeCell in SW). This results in a strong decrease of velocity due to a large increase in the number of curvatures along the flagellum as illustrated in Fig. 3: from 5-6 in normal SW (Fig. 3c), the number of curvatures rises up to 10-11 (Fig. 3f) in viscous solution; Fig. $3 \mathrm{~b}$ shows exponential increase of viscosity when increasing of MeCell concentration; the latter obviously leads to a decrease in other parameters: wave length or amplitude and consequently velocity (not detailed). As similar effects of MeCell are observed neither with turbot demembranated spermatozoa (Cosson et al. 2008b) nor with sea urchin or tunicate sperm (Brokaw 1966), MeCell effects could result from the ribbon-shaped flagella specific to native fish spermatozoa due to the presence of fins that greatly increase the surface of viscous interaction with the surrounding medium. Thus, increased viscosity leads to an increase of wave numbers in native spermatozoa of cod and sea bass (Cosson et al. 2008b). Such viscous medium mimics the situation occurring for sperm cells in fluids such as ovary fluids or jelly-like layers that surround eggs in some fish species.

A major and general change occurring to the wave shape of marine fish spermatozoa in SW is the dampening process; it is accompanied in some species by asymmetry of beating.

Flagellar waves are almost planar, i.e., each sine wave is 'flat' and the successive waves are coplanar. The waves are also most of the time coplanar with the plane of observation, which is the focal plane of the objective lens and which usually coincides optically with the glass slide plane as well as that of the cover slip. An exception to wave's flatness is found in eel spermatozoa in which waves are of corkscrew shape, i.e., helicoidal (Gibbons et al. 1985, Wooley 1997, 1998). Even though eel spermatozoa swim with very high $\mathrm{BF}, 95 \mathrm{~Hz}$, their original wave pattern of helicoidal shape is poorly efficient in terms of forward velocity. They mainly present a rolling motion at $19 \mathrm{~Hz}$, and flagella develop a 3D bending, recently detailed by Wooley (1998).

A more detailed analysis of the exact shape of the flagellum during motion can be obtained by determining the local curvature of the flagellum and plotting the curvature versus the distance on the flagellum (Cosson 2004).

The flatness of waves is not perfect, but waves slightly deviate from the plane; this was shown in sperm flagella

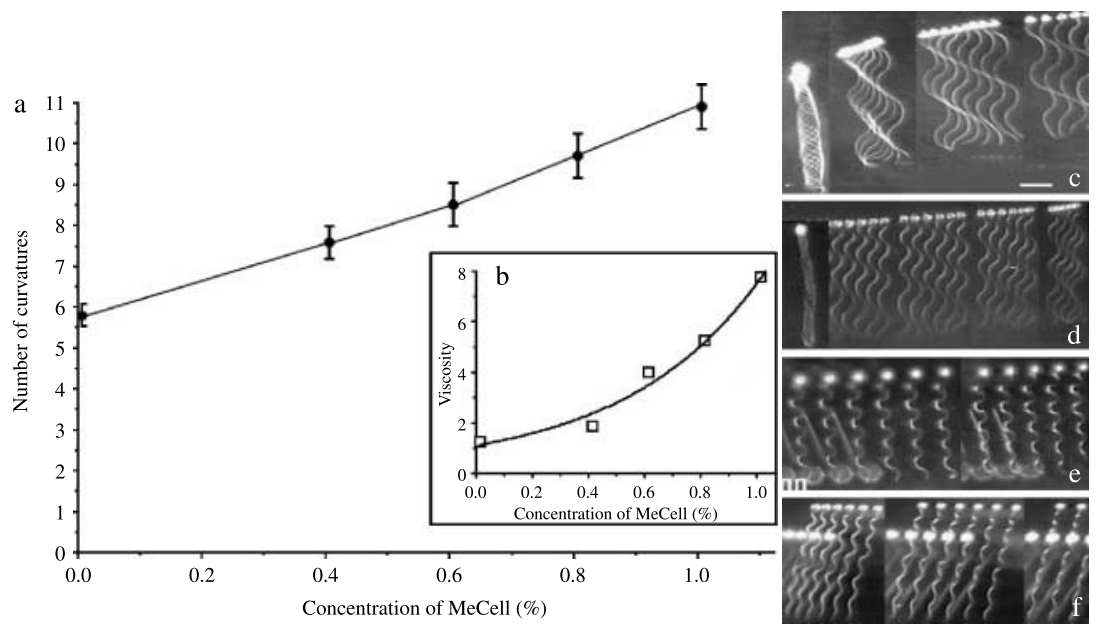

Figure 3 The effects of viscosity on the wave parameters of turbot sperm flagella. (a) Plot of the number of twists along the flagellum as a function of the concentration of methyl cellulose (MeCell). (b) The relationship between viscosity (in decipoises as measured with a viscosimeter) and MeCell concentrations. (c-f) Successive images of an individual spermatozoon obtained every $3 \mathrm{~ms}$ (from left to right in each) at various MeCell concentrations: (c) no MeCell in SW, (d) $0.6 \%$ MeCell, (e) $0.8 \%$, and (f) $1 \%$. Scale bar: $10 \mu \mathrm{m}$. 
of several species including marine fishes (Cosson et al. 2003). Such slight distortion is in the shape of alternating helical segments and is designed in such a way that each linear segment intercalated in between two successive curvatures generates a thrust that is not coplanar with the main beating plane: as a result, while swimming, sperm cells have the tendency to be pushed by their flagella toward surfaces, and then to remain swimming in the vicinity of these surfaces. This presents an advantage for observers because sperm cells remain in focus very close to the glass slide plane (usually the focal plane of the microscope). But the drawback is that a majority of spermatozoa swim in the vicinity of these surfaces, which lead to a bias when counting the moving spermatozoa by automatic techniques such as CASA. Such an ability to swim in the vicinity of the egg surface can be a biological advantage for fertilization efficiency. Swimming close to a surface frequently leads to the adhesion of sperm to glass; in order to make sure that spermatozoa can swim freely, prevention of sticking to glass surfaces can be ensured by the addition of BSA (at $0.1-0.5 \%$ ) or Pluronic F-127 (at 0.1\% from Sigma).

Another type of wave distortion is also observed, when turbot or sea bass sperm are exposed to pollutants such as mercury derivatives (see in Fig. 5).

\section{The symmetry of flagellar waves and their dampening usually evolves during the motility period}

Another characteristic of beating flagella is the ability to develop either symmetric or asymmetric ways of beating: waves follow each other and successive waves are called direct and reverse waves (Gibbons 1981). When both are of equal curvature, symmetrical movement is developed and forces the sperm cells to describe linear tracks. In case of unequal curvature, movement becomes consequently circular and sperm cells describe circles of corresponding diameter (Brokaw 1991a). This is observed in sea bass sperm flagella, in vivo as well as in vitro (Dreanno et al. 1999b) and in tuna sperm (this paper). In all cases, asymmetry of beating is related to $\mathrm{Ca}^{2+}$ regulation.

During the motility period, the wave pattern of fish spermatozoa rapidly evolves (Fig. 2) successively from a fully beating pattern, where waves propagate along the whole length of the flagellum, to a partially beating pattern, where waves occupy only the portion of the flagellum proximal to the head, finally leading to the full absence of any beating wave (Cosson et al. 1997, 1999). The blocking process occurs to the distal part of the flagella at a precise time post-activation (20-30 s or later depending on species). The distal part of the partially beating flagellum appears straight, rigid, and devoid of any propagating wave (Fig. 2). The fully developed waves are initiated and propagated in the proximal segment of the flagellum over a distance covering one-third to one-fourth of the total length (Fig. 4). Such a decrease of the wave amplitude (WA) along the flagellum from the proximal to distal part is called 'wave dampening'. Flagellar wave dampening also occurs in invertebrate spermatozoa and was described more extensively by Tombes et al. (1987) in sea urchin flagella. In turbot spermatozoa, the wave
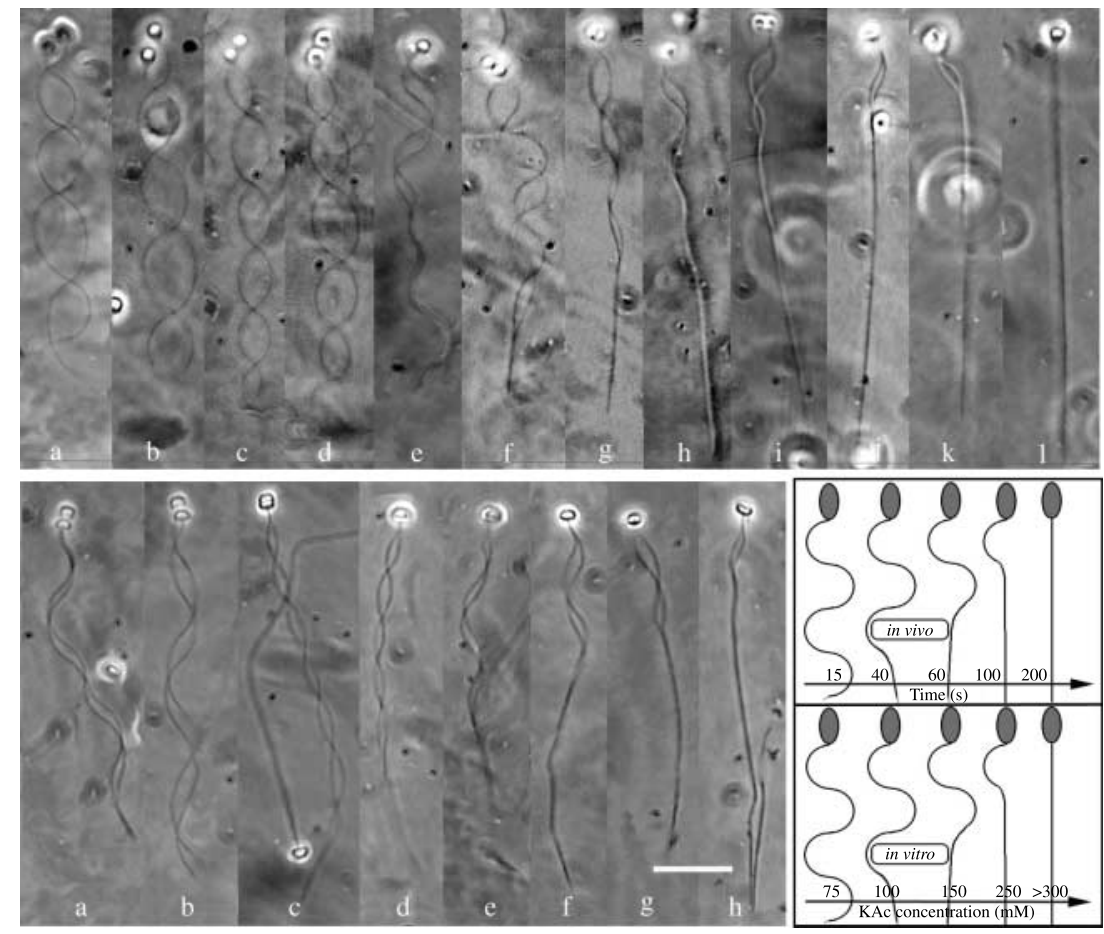

Figure 4 Wave shape of turbot sperm observed in vivo and in vitro. Upper panel: (a-d) just after the triggering of motility, fully developed waves occupy most of the length of the flagellum; their amplitude is constant and their frequency remains high; $(\mathrm{e}-\mathrm{g})$ at the middle of the motility phase, the frequency drops while the wave propagation becomes restricted to the proximal part of the flagellum and the very tip of the flagellum is in rigor; ( $h-k)$ waves develop only in a very short portion close to the head; and (I) no wave remains and the whole flagellum stops beating; it adopts a rigor aspect. Lower panel: demembranated flagella reactivated by ATP- $\mathrm{Mg}^{2+}$ and exposed to increasing (from left to right) concentration of salt ( $\mathrm{K}$ acetate in this example): the dampening of waves occupies a segment of increasing length on the distal flagellum. Scale bar: $10 \mu \mathrm{m}$. Bottom right: schematic of the progression of the wave shape in fish sperm flagella during the swimming period in vivo (upper part of the panel) and in vitro (lower part of the panel). 
dampening is also induced in vitro on demembranated flagella by the non-adequate ionic strength (Fig. 4): by contrast, ionic concentration shows little effect on trypsin-induced microtubule sliding (an in vitro measurement of dynein activity), BF, and proximal WA. In turbot sperm, this dampening is not related to $\mathrm{Ca}^{2+}$ induction of beat asymmetry as no sensitivity to this ion has been observed. Dampening occurs because waves persist preferentially in the portion of the flagellum close to the head. The observations of wave dampening obtained in vivo and in vitro on turbot sperm flagella (Fig. 4) show traits common to sperm of most other fish species (Cosson et al. 1997, 1999).

The rigidification process following dampening observed for turbot spermatozoa by Chauvaud et al. (1995) has been hypothetically related to the energy distribution in the flagellum at the end of the motility period (see paragraph on energetics): the ATP level would then be lower than the initial level, while that of ADP would be higher, as a consequence of ATP hydrolysis during the motility phase. Published results show that all the elements necessary for the functioning of a phosphocreatine ( $\mathrm{PCr}$ ) shuttle are present in turbot as well as in trout spermatozoa (Saudrais et al. 1998). This shuttle would allow a more homogenous distribution of ATP along the flagellum. However, as emphasized above, dampening also occurs in vitro in demembranated spermatozoa, where no such shuttle can be active. In the case of turbot sperm, a similar sequence of wave dampening leading to full stiffening can also be precociously induced by $\mathrm{CO}_{2}$ application (Dreanno et al. 1995, Inaba et al. 2003). Independently, it is also possible to trigger dampening in vivo in demembranated/reactivated flagella by adjustment of ionic concentration as detailed below. In the latter situation, ATP concentration is not responsible because, in vitro, it remains constant and at a value close to $1 \mathrm{mM}$ as explained in the next paragraph.

\section{Flagellar BF and efficiency both decrease during the motility period}

The BF represents the number of waves generated every second; the BF is directly in proportion to the activity of dyneins and therefore of the rate of ATP hydrolysis. In the six species described in this paper, the BF shows high values at initiation of motility, but decreases rapidly as a function of time.

Fish sperm advantageously exhibits a high homogeneity of movement in the sperm population at a given time point; that is, the successive images of one single sperm cell are representative of the majority of the population but this is only true when considering any defined time point after activation. This is mainly obtained by the use of a double dilution procedure (first dilution of milt in a non-swimming solution followed by a second dilution in the SM), which allows homogeneity and synchrony in the motility initiation for the whole population of sperm cells.

Within a very brief period, i.e., less than $3-5 \mathrm{~s}$, the minimal period of time required to achieve the second dilution and mixing, motility is initiated for almost $100 \%$ of the spermatozoa. This initial swimming period, which lasts 5-60 s depending on the species, is characterized by the high $\mathrm{BF}$ (up to $70 \mathrm{~Hz}$ ) of fully developed waves proceeding throughout the whole flagellar length with an almost constant amplitude (Figs 2 and 4). These characteristics are similar to those of the sea urchin's sperm flagellum, which is commonly used as a model for sperm movement studies (Gibbons 1981). In the sea urchin, such behavior is constantly exhibited for very long periods of time, i.e., hours, with BF of $45 \mathrm{~Hz}$. The wave dampening features mentioned for turbot sperm as example occurs in all teleosts fish spermatozoa so far studied (Cosson et al. 1997, 1999). After a first period post-activation, fish sperm show a decrease not only in $\mathrm{BF}$, in the case of Oncorhynchus mykiss sperm (Cosson et al. 1985, 1991), for Acipenser baeri sperm (Cosson et al. 1995b) and for Scophthalmus maximus (Chauvaud et al. 1995) but also in WA in the distal portion of the flagellum (Cosson et al. 1999) as clearly demonstrated in turbot (Fig. 2).

After a first period post-activation, fish sperm show a decrease not only in BF but also in WA in the distal portion of the flagellum (Cosson et al. 1999; Fig. 4). The flagellar beat efficiency is a measurement of the propulsive efficiency or swimming performance; it represents a combination between the BF and the WA. The combination of decrease in BF and WA leads to a faster decrease of the swimming performance $(P)$, because $\mathrm{P}=\mathrm{BF} \times \mathrm{WA}$. This process is accelerated as the time progresses within the movement period, because waves travel in a more and more restricted part of the proximal flagellum, while a longer and longer distal part becomes inactive and straight. This is clearly illustrated in turbot spermatozoa where the distal straight segment occupies $60-80 \%$ of the length or even the total length by the end of the translational motility period. This local paralysis may be paralleled by a curling process similar to that also observed in carp sperm (Perchec et al. 1996): the appearance of such a distal loop represents an additional contribution to the rapid slow down of sperm cells; it is followed by a full arrest. Nevertheless, both the rigidification and the curling are reversible processes; this reversal is obtained when sperm cells are transferred from SM (high OP) back to IM (low OP). The reversibility process is related to both reconstitution of energy stores and internal ionic concentration. A subsequent transfer to SW needs to be applied after a delay in IM, during which cells reload their ATP and their ionic levels to a normal value compatible with full motility (Dreanno 1998, Cosson et al. 2008b). This delay probably involves both mitochondrial respiratory activity and ion-pumping activities, the latter being also ATP dependent. 
Energy stores are allowed to reconstitute during the incubation in an opposite OP situation (sustaining no motilility) and this allows a second motility sequence to be triggered through a new transfer in SW. Sperm flagella exhibit a new full wave pattern with normal waves developed and high beat efficiency. The hypothesis of such a restoration of the initial energy store has been confirmed by the direct measurement of the ATP concentration (see below), which shows a low value at the end of the first motility phase compared with that obtained after regeneration; this was observed for the sperm of $S$. maximus (Perchec et al. 1993, Suquet et al. 1994, Chauvaud et al. 1995) similarly to observations in fresh water species such as O. mykiss (Christen et al. 1987, Billard \& Cosson 1992), or Cyprinus carpio (P A second activation of motility can also be induced in spermatozoa from Ictalurus punctatus (Guest et al. 1976).

\section{The regulation of axonemal motility by ionic concentration can be observed in vitro}

Complementary information leading to the understanding if this specific in vivo behavior comes from experiment using demembranated sperm models; wave parameters of permeabilized models were measured in the presence of a variable concentration of ions. We mostly observed that in vitro wave patterns can mimic those of in vivo flagella depending on two kinds of parameters: the general and non-specific ion concentrations so called ionic strength and the $\mathrm{Ca}^{2+}$ concentration. The ionic strength mostly controls two aspects of wave shapes: activation and wave dampening, while the $\mathrm{Ca}^{2+}$ concentration mostly governs the asymmetry of beating, i.e. the circling of sperm cells or sperm models.

Below we detail these results on the in vitro sperm models of two species (turbot and sea bass), because they are crucially important to better understand the two main features specific to fish sperm: the mechanism of activation and the briefness of motility, and finally give rise to a common model allowing an explanation of both features.

In vitro wave patterns are shown in Fig. 4: the WA, the wavelength as well as portion of the flagellum where waves fully develop are all controlled by the ionic concentration of the RM. Briefly, when increasing ionic concentration, waves activity parameters vary successively from zero to an optimal value, then decrease more and more down to zero again at much higher ionic concentrations. As in vivo motility can be triggered in no electrolyte solutions with osmolality higher than $300 \mathrm{mOsm} / \mathrm{kg}$, a potent effect of osmolality on axonemal machinery was tested. When glucose, sucrose, or mannitol were added at up to $500 \mathrm{mM}$ to the reactivation solution (containing $75 \mathrm{mM} \mathrm{KAc}$ as major ions) neither distal blockage nor perturbation of the wave shape or the frequency were observed. By contrast, media containing glucose from 10 to $500 \mathrm{mM}$ but no KAc did not allow any flagellar motility. It is concluded that the effects observed in vitro are not due to a direct sensitivity of axonemes toward osmolality. In order to identify which element of the axonemal machinery is affected by ionic strength, experiments of microtubule sliding were conducted. When KAc concentration was varied from 25 to $250 \mathrm{mM}$, little effects of ionic strength were observed neither on the portion of the flagellum where sliding occurred (distal versus proximal) nor on the rate of sliding (Cosson et al. 2008b); dynein itself would not be the direct target of ionic effects. The same is concluded for the $\mathrm{CO}_{2}$ effects, either in turbot (this paper) or in sea urchin sperm (Brokaw \& Simonick 1976).

The variations of $\mathrm{BF}$ of axonemes reactivated in the presence of various ATP- $\mathrm{Mg}^{2+}$ concentrations indicate that the $K_{\mathrm{m}}$ for ATP and the corresponding $V_{\mathrm{m}}$ are unchanged when KAc concentration varies from 25 to $250 \mathrm{mM}$. These results could tend to show that the axonemal component preferentially blocked by the increasing ionic strength could be some dynein subspecies located in the distal portion of the axoneme, as observed in Chlamydomonas flagella (Piperno \& Ramanis 1991). Nevertheless, our in vivo observations show that in some cases, only distal portions of the flagellum can be active (Cosson et al. 2008b) and do not favor such a hypothesis.

In similar assays using demembranated turbot spermatozoa, in vitro reactivation media made of $\mathrm{KCl}$, $\mathrm{K}$ propionate, and $\mathrm{NaCl}$ gave equal results but $\mathrm{K}$ acetate was preferred because sperm motility was more stable, as already stated for sea urchin spermatozoa in such media (Gibbons et al. 1982, Gibbons \& Gibbons 1983). These assays also showed that $\mathrm{K}^{+}$ions, even at high concentrations, are not inhibitors of the reactivated movement. The absence of inhibitory effects of $\mathrm{K}^{+}$also holds for trout (Saudrais et al. 1998) and carp demembranated sperm models (Cosson \& Gagnon 1988) and therefore cannot explain the $\mathrm{K}^{+}$blocking effect observed in vivo in trout. In turbot, other ions were also tested, such as $\mathrm{NaHCO}_{3}$ at concentrations from 2.5 to $50 \mathrm{mM}$. When combined with the optimum reactivation medium containing 50-75 mM KAc, no effect was observed with 1-5 $\mathrm{mM} \mathrm{NaHCO}$, but a progressive blockage of the axoneme in its the distal part was shown when higher $\mathrm{NaHCO}_{3}$ concentrations were used. These results confirm an effect of the ionic strength on distal blockage of the axoneme as $\mathrm{NaHCO}_{3}$ contributes more efficiently to the ionic strength (3 meq/molecule). The $\mathrm{pH}$ was controlled and it was little affected by the addition of $\mathrm{NaHCO}_{3}$. The results obtained in vitro with $\mathrm{NaHCO}_{3}$ will be discussed later for comparison with in vivo effects of $\mathrm{CO}_{2}$.

The results of the in vitro experiments with sea bass demembranated flagella show effects of $\mathrm{Ca}^{2+}$ ions combined with effects of ionic strength on the circularity of tracks, as seen in many species (Brokaw 1991a). 


\section{The energy available in marine fish spermatozoa is rapidly exhausted}

For details about the energetics of fish spermatozoa, readers can find details in Gosh (1985) and in the general review of Billard \& Cosson (1990).

A common feature is the decrease in sperm ATP content during the motility period. Presently, most studies in marine fishes concern turbot (Dreanno et al. 1999c) and sea bass. In sea bass, ATP values of $1.22 \mu \mathrm{mol} / \mathrm{mg}$ protein (Zilli et al. 2004) were observed. It is difficult to correlate with the previously published results of $90 \mathrm{nmol} / 10^{9}$ spermatozoa by Dreanno et al. (1999b) due to the difference of unit. Dreanno et al. (1997) and Zilli et al. (2004) have proposed to use ATP as a sperm quality marker for sperm used for cryoconservation.

In turbot, the ATP content is dependent on an aging phenomenon related to the maturity period (Suquet et al. 1997, Dreanno et al. 1999a). Usually, ATP content is around $200 \mathrm{nmol} / 10^{9}$ spermatozoa (Dreanno et al. 1999b). In turbot, inhibitors of respiration (KCN) or ATP synthesis (oligomycin) have little effects on the internal ATP concentration.

The adenylate energy charge (AEC), a measurement of the percentage of energy present in ATP and ADP relative to adenylate compounds (Atkinson 1968), decreases from $90-95 \%$ at activation by SW to $50 \%$ at 1 min postactivation (Dreanno et al. 1999c).

Nuclear magnetic resonance studies on turbot spermatozoa (Dreanno et al. 1999c, 2000) show that other energetic compounds such as creatine phosphate contribute to the energetic balance during motility. The presence of creatine kinase was described in turbot spermatozoa and therefore a $\mathrm{PCr}$ shuttle is probably present in turbot as well as in trout spermatozoa (Saudrais 1996, Saudrais et al. 1998) allowing a more homogenous distribution of ATP along the flagellum. This shuttle involves ATP/ADP and creatine/PCr is similar to that described in sea urchin sperm (Tombes et al. 1987). In turbot, the presence of $\mathrm{CO}_{2}$ also affects the internal ATP level.

In hake sperm, preliminary results (Groison et al. 2007) indicate AEC initial value of 0.71 before motility activation, with a large individual variability from 0.17 to 0.96. In other species such as cod and tuna, no information is available.

In turbot, the ATP concentration in vivo can be calculated from the ATP content per cell: assuming a volume of $16 \times 10^{-9} \mu \mathrm{l}$ per sperm cell (Christen et al. 1987) supposedly constant during motility, the results of Dreanno et al. (1999c) lead to 6 mM ATP and 2 mM ADP initial concentration; in arrested spermatozoa, the ATP drops down to $1.5 \mathrm{mM}$. The $K_{\mathrm{m}}$ of ATP for the dynein ATPase is about $150 \mu \mathrm{M}$ and plateaus at $80 \mathrm{~Hz}$ (extrapolation of $f_{\max }$ Cosson et al. 2008b). In halibut demembranated sperm flagella, $K_{\mathrm{m}}$ ATP is $170 \mu \mathrm{M}$ with $f_{\max } 51 \mathrm{~Hz}$ (Billard et al. 1993). In eel, $K_{\mathrm{m}}$ ATP is
$150 \mu \mathrm{M}$ with $f_{\max } 83 \mathrm{~Hz}$ (Gibbons et al. 1985). In eel spermatozoa, the dynein ATPase is located in axonemal inner arms only (Baccetti et al. 1979), outer arms being absent. In turbot, at the end of the motility period, the intraflagellar ATP concentration drops down spectacularly but it is still high enough to sustain motility, while ADP $(2 \mathrm{mM})$ is not high enough to fully inhibit the dynein activity by competition with ATP.

The respiration rate of marine fish sperm is boosted at activation. This was measured in few species because of the briefness of the motility period relative to the time period needed to obtain this respiration rate using an oxygen electrode. In turbot, this is possible because motility lasts long enough: initial respiration ranges $35 \mathrm{nmol} \mathrm{O}_{2}$ per min per $10^{9}$ spermatozoa but at transfer in SW, it reaches 135 (same units) and then decreases to 40 at 2 min (Dreanno et al. 1999c). In cod, respiration at rest is of 1.5-3 (same units, Robitaille et al. 1987). The effect of respiratory inhibitors are detailed in Dreanno et al. $(1999$ c): FCCP or KCN does not affect respiration of swimming spermatozoa; oligomycin is of low inhibitory effect; and $\mathrm{KCN}, \mathrm{NaN}_{3}$, or $\mathrm{NaHCO}_{3}$ does not affect motility or flagellar BF.

Marine fish spermatozoa are able to sustain a second motility period after a certain period of rest, provided previously activated spermatozoa remain metabolically active. In turbot, the revival of spermatozoa rendered immotile by a first incubation in SW can be obtained by allowing these cells to settle in an artificial SF (Cosson 2004). After a subsequent transfer into SW, spermatozoa reinitiate motility and swim similarly to the first activation in SW. This second transfer needs to be applied after a delay, during which cells reload their ATP level (Dreanno 1998, Cosson et al. 2008b). This delay probably involves both mitochondrial respiratory activity and ion-pumping activities, the latter being both ATP and motility dependent.

\section{The ultimate task for sperm is to meet an egg: how to attract sperm and guide it to micropyle}

Even though one generally believes intuitively that sperm is attracted by egg, there are very few examples of the demonstration of such phenomenon, so-called chemotaxis: this has been well established in sea urchins, several jelly fishes, and ascidians (Bohmer et al. 2005, Kaupp et al. 2006, Shiba et al. 2006). In fish, the only clear demonstration is in the pacific herring (Clupea pallasi); spermatozoa are not active when delivered at spawning in SW but only when they happen to reach the egg chorion, more precisely the vicinity of the micropyle (Yanagimachi 1957, Yanagimachi et al. 1992, Griffin et al. 1996). The motility initiation is regulated by a reverse $\mathrm{Na}^{+} / \mathrm{Ca}^{2+}$ exchanger (Vines et al. 2002) but some components of the chorion are needed (Oda et al. 1995): the herring sperm activating peptide (HSAP) and the sperm motility initiation 
factor (SMIF). The HSAP has protease inhibitor motifs (Oda et al. 1998) which binds to an endopeptidase of the flagellar membrane (Yoshida et al. 1999). The SMIF is a $105 \mathrm{kDa}$ glycoprotein localized in the chorion part surrounding the micropyle that induces a trajectory switch from linear in 'free' SW to helicoidal in the micropylar funnel. Such a specific sperm/egg behavior could be related to the spawning behavior and the male/female reproductive biology traits in this species (Stacey \& Hourston 1982, Hay 1985).

Physicotaxis is necessary for physical guidance of sperm cells on the surface of eggs and eventually toward the micropyle. The first aspect of physicotaxis is the tendency for spermatozoa to swim on any surface, including the surface of an egg, which at this scale appears large and flat. This ability to swim in the close vicinity of surfaces is due to a slight deviation of the beating plane of sperm flagella, which generates a thrust of small amplitude out of the main beat plane and leads to a chiral shape in two successive helices inverted relative to each other (Cosson et al. 2003). The consequence is that spermatozoa at surfaces mostly follow two dimensional tracks instead of three dimensional ones when swimming in space in the absence of any surface (for example in turbot; J Cosson \& E Corset, unpublished observations), following the egg surface highly increases the chances for any spermatozoon to reach the micropyle. These chances are further improved by the presence of guidance grooves located on the surface of some eggs. Such guidance tracks physically converge toward the micropylar funnel, resulting in fine into a significant increase of sperm concentration in the close vicinity of the micropyle (estimated to $10 \mu \mathrm{m}$ range in turbot eggs; Cosson et al. 2008b). This was also documented in some fresh water species such as Puntius conchonius (Amanze \& lyengar 1990) and medaka (Iwamatsu et al. 1993).

In addition to the delivery of DNA information through the egg micropyle, the ultimate task of the fish spermatozoon would be to induce a factor responsible for $\mathrm{Ca}^{2+}$ waves in the eggs, a necessary signal for egg activation (Coward et al. 2003).

\section{The ability of spermatozoa to fertilize eggs: limitations to the fertilization process}

In order to meet the egg, sperm should come into its vicinity, therefore the total averaged distance covered (called $D$ ) by sperm cells is a key factor. $D$ can be calculated from the change in velocity with time by use of the formula:

$D=\int_{t_{0}}^{t_{e}}\left(-\frac{v_{0}}{t_{0}} \times t+v_{0}\right) \mathrm{d} t$

Integral calculation needs first a curve fitting of the plot of velocity versus time after activation. In theory, this calculation must take into account the linearity index weighted according to the percentage of motility decrease. As tracks are usually not linear but circular, the efficient distance covered is even lower than that predicted by calculation. From the above formula, one can also predict that when velocity decreases logarithmically with time (the most common case), 80-90\% of the distance is covered by sperm during the first half of the motility period $\left(D_{1 / 2}\right)$.

A gross estimation of the distance covered by a spermatozoon is $2.3 \mathrm{~mm}$ in sea bass (Dreanno et al. 1999b), $12 \mathrm{~mm}$ in turbot (Chauvaud et al. 1995), $14 \mathrm{~mm}$ in cod (this paper), $11 \mathrm{~mm}$ in hake (this paper), $10 \mathrm{~mm}$ in tuna, and $9 \mathrm{~mm}$ in halibut (Billard et al. 1993). Trippel \& Neilson (1992) estimated an initial velocity of $2 \mathrm{~mm} / \mathrm{min}$ for turbot, which leads to a total distance of 4-6 mm after integration during the motility period.

Compared with many other oviparous animal species, the egg size of marine fishes is relatively small but definitely big when compared with the spermatozoon size. The egg diameter is (in $\mathrm{mm}$ ) 1.02-1.39 (Carillo et al. 1995) and 1.16-1.89 in sea bass (Kjorsvik \& Holmefjord 1995), 1.2-1.8 (Miller et al. 1995) in cod, 3.00-3.80 in halibut (Kjorsvik \& Holmefjord 1995), 1.06 \pm 0.10 (AL Groison, M Suquet \& J Cosson, unpublished observations) in hake, 1.4-3.5 (Ehrenbaum 1905) or 1.01-1.07 in turbot, and 1.0-1.2 in red tuna (Doumenge 1999).

Comparison of egg size relative to the distance covered by a spermatozoon leads to similar values; therefore, any marine fish spermatozoon should be delivered in the close proximity of the ovocyte in order to reach its micropyle. This may explain a double reproductive strategy for marine fishes in order to accomplish the reproductive task: (1) a very large excess of sperm cells relative to one egg and (2) a local delivery of sperm resulting from a close proximity between the two spawners, male and female.

Obviously, the fertilizing ability not only depends on the ratio of the number of active spermatozoa per egg but also of the time elapsed since motility activation (Fauvel et al. 1999). In turbot, after a 3-min period of sperm swim, the number of swimmers decreases: the efficiency for fertilization decreases, reaching zero after tens of minutes. The fertilization ability of gametes is one among other traits of the reproductive biology of fishes; in this regard, specific information concerning fish mating can be found in Rakitin et al. (2001) about cod in Murua \& Motos (2006) about hake and more generally in Turner (1993).

\section{Sperm movement specificities in some species: effects of $\mathrm{Ca}^{2+}$ and $\mathrm{CO}_{2}$}

As seen in sea bass, tuna and tilapia (Morita et al. 2003), sperm motility relies on both external osmolality and external $\mathrm{Ca}^{2+}$ concentration. Influx of $\mathrm{Ca}^{2+}$ across the plasma membrane is a common mechanism of $\left(\mathrm{Ca}^{2+}\right)_{i}$ 
signaling exploiting the limitless extracellular reservoir of $\mathrm{Ca}^{2+}$, SW where it ranges $11 \mathrm{mM}$. In addition, some membrane vesicles containing calreticulin $\mathrm{a} \mathrm{Ca}^{2+}$ storage protein; Ho \& Suarez 2003) and a $\mathrm{Ca}^{2+}$ mobilization system $\left(\mathrm{Ca}^{2+}\right.$ activated Ca channels; Harper et al. 2004) were described. Selective localization of the various types of plasma membrane channels that permit $\mathrm{Ca}^{2+}$ influx provides some flexibility. The expulsion of an excess of $\mathrm{Ca}^{2+}$ through the plasma membrane relies on the ATPdriven $\mathrm{Ca}^{2+}$ pumps and $\mathrm{Na} / \mathrm{Ca}$ exchangers. $\mathrm{A} \mathrm{Ca}^{2+}$ ATPase pump is present in the mid piece region of sea urchin sperm, i.e., the mitochondrion (Gunaratne \& Vacquier 2006). These data reveal a level of complexity in sperm $\mathrm{Ca}^{2+}$ signaling that rivals those of larger and more complicated cells.

Flagella can change their beating pattern (asymmetric or symmetric) in response to $\mathrm{Ca}^{2+}$ concentration perceived by the axoneme (Brokaw 1991a), which contains several calcium binding proteins: calmodulin in the spokes (Yang et al. 2001), centrin (caltractin) at the attachment point of the $I 2$ and $I 3$ inner dynein heavy chains (dynein regulatory complex; LeDizet \& Piperno 1995), all elements by which asymmetry of flagellar beating could be controlled by $\mathrm{Ca}^{2+}$ in marine fish sperm.

The main $\mathrm{CO}_{2}$ effect is a blockage of axonemal motility both in vivo (Dreanno et al. 1995) and in vitro: this is specific to flatfishes, including turbot, due to the high concentration of carbonic anhydrase in their sperm flagella (Inaba et al. 2003). Both in vivo and in vitro, $\mathrm{CO}_{2}$ controls dynein activity through a $\mathrm{NaHCO}_{3}$ ionic effect similar to that of the other ions (Dreanno et al. 1999d). In the sea urchin's sperm flagella, $\mathrm{CO}_{2}$ was also shown to affect wave shape without blockage, therefore probably involving a different mechanism (Brokaw \& Simonick 1976, Brokaw 1977).

Additional signaling such as protein phosphorylation was shown to be involved in flagellar motility regulation (Inaba 2003) but little is known in this respect in marine fish spermatozoa. In striped bass, flagellar activation seems to occur through phosphorylation of some specific proteins via a cAMP-independent pathway (Shuyang et al. 2004); similar results were observed in tilapia (Morita et al. 2006). Viviparous fish like guppy (Poecilia reticulata), a fresh water species, adopt a strategy requiring CAMP signaling, but it needs application to the spermatophore of some chaotropic chemicals that destabilize specific flagellar protein(s) (Tanaka \& Oka 2005) to reach motility activation.

Flagellar shape modifications, i.e., stiffening of distal part of fish sperm flagella, could result from a regulation by hydin, a central pair protein of cilia and flagella (Lechtreck \& Witman 2007).

\section{The osmolarity control of motility: toward a global explanatory model}

Osmolality effects on fish motility have been studied by Morisawa (1994) and Perchec-Poupard et al. (1997) in marine and fresh water species. Regarding osmolality adaptation of marine fish spermatozoa it is worth to remind the presence of membrane folding which develops in most species on both sides of the flagellar membrane. These fins flank the whole length of the flagellum, ranging to several micrometers in width, and obviously increase the ratio surface to volume of the flagellar organelle. Not only do they contribute to the efficiency of the thrust generated by waves by increasing the flagellar surface used for the friction on the surrounding medium during movement, but they also contribute to a large increase of the membrane surface when compared with a simple cylindrical axoneme. A calculation applied to turbot flagellum leads to the following: the surface of a flagellum in shape of a simple cylinder is about 34 millions square nm; this is about one-fourth compared with the surface of the same cylinder comprising fins (160 millions square $\mathrm{nm}$ ). This 'excess' of surface has large implications in the water exchange/osmotic regulation of sperm. At initiation of movement of marine fish spermatozoa in SW, the first signal received by the membrane is osmotic, followed by a water flux in either direction, or provokes local membrane distortions due to osmotic constraints. A significant increase of the membrane surface due to these fin-shaped creases (Cosson et al. 1999, Cosson 2007b) favors water exchange. The distortion ability of creases would lead to the blebs or coils observed on exposure to extreme osmotic situations (Perchec et al. 1996, Cosson et al. 2000).

Subsuming the above remarks on marine fish sperm, we have developed the following model to explain motility activation then inhibition resulting from non-optimal internal ionic concentration, according to in vitro results. Sudden exposure of an animal cell to an extreme and drastic osmotic environment, i.e. SW, causes various reactions including volume and shape changes because, in contrast to vegetal cells, they are devoid of the constraints of a polysaccharide wall (Stein 2002). By the OP effect, sperm motility in marine fishes is induced by the hyperosmotic shock of the surrounding medium (Billard et al. 1993, Chauvaud et al. 1995, Gwo 1995, Linhart et al. 1999, Krasznai et al. 2003, Cosson $2007 b)$. Nevertheless, sperm motility is triggered in turbot and other flatfish in isoosmotic as well as in hyperosmotic media (Suquet et al. 1994) relatively to the SF because of the extra control by $\mathrm{CO}_{2}$. Motility occurs in a wide range of osmolalities, below or above that of SW (Suquet et al. 1994, Billard et al. 1995, Chauvaud et al. 1995): optimal osmolality (in $\mathrm{mOsm} / \mathrm{kg}$ ) is at 900 1100 in halibut (Billard et al. 1993), 300-1100 in turbot, 333-645 in tilapia (for fishes raised in SW, Linhart et al. 1999) but higher for tilapia fish raised in hypersalinity (Legendre et al. 2008), and 480 in Atlantic croaker (Vizziano et al. 1995). A general model of marine fish sperm motility control by osmolality is proposed in Fig. 6, where turbot sperm is taken as an example. It is based on results published by Suquet et al. (1994), 
Chauvaud et al. (1995), and Inaba et al. (2003) as well as additional in vitro result.

In some cases, resistance to very low osmolality is surprisingly high; turbot sperm can sustain dilution in distilled water and resist reversibly for several minutes. Osmolality is definitely a key factor for fish gametes released in the surrounding medium. In marine fish oocytes, the permeability diffusion $\left(P_{\mathrm{d}}\right.$ in $\left.\mu \mathrm{m} / \mathrm{s}\right)$ was estimated in salmon to 1.68 at release in water but shown to decrease to 0 within 20 min from contact with water (Prescott 1955). This was confirmed in marine teleosts by the use of radioactive tracers (Potts \& Eddy 1973) where stretch receptors and aquaporins are supposed to play this regulatory role probably in contrast to that occurring in spermatozoa as discussed below.

In the case of male gametes, it is worth mentioning that mechanical activation could be the second signal in response to the first (osmotic) signal via the stretchactivated channels (SACs) located in the sperm membrane. It has been shown that a specific and reversible inhibitor of the SACs, gadolinium, is active on carp spermatozoa (Krasznai et al. 2003), and more generally in spermatozoa of several fish species including marine ones such as sea bass, turbot, and tuna (Cosson et al. 2008b), but inactive in sperm of other species apart from fishes (Krasznai et al. 2003). SACs are mechanosensitive channels that increase the membrane conductivity to ions such as $\mathrm{Ca}^{2+}$ or $\mathrm{K}^{+}$ when mechanical constraints induce distortion of this membrane (Yang \& Sachs 1993). Mechanosensitivity is biologically important (Ingber 2006) especially considering that flagella and cilia are acting as mechanosensitive detectors: the signal is transduced through gene products of the polycistic kidney disease family (Pan et al. 2005). By proteomic analysis, the presence of a polycystin-2-like receptor was revealed in Chlamydomonas cilia (Pazour et al. 2005) and in metazoan cilia as well (Pazour \& Rosenbaum 2002); in addition polycystin-2 is a 'transient receptor potential', a cation channel with mechanosensory properties (Nauli et al. 2003). Mechanosensitivity is also a specific property of flagellar axonemes; no longer beating cut-off pieces of axoneme that have lost coordination can be reinitiated by bending the flagellum with a microprobe (Lindemann \& Rickemenspoel 1972). In fish spermatozoa, the same situation probably occurs when sperm are put in a medium limiting the initiation of motility. Activation by SW probably involves such mechanosensitivity; at first, mechanosensitive channels are activated which themselves mechanically activate the axoneme (Fig. 6).

The SACs may associate with other membrane proteins to modulate their activity (Vandorpe et al. 1994); those can be water channels (aquaporins) that are involved in the water transportation across membranes and may increase up to 1000 -fold the diffusion rate of water molecules through membranes. In fish spermatozoa, the putative presence of aquaporins comes from observations where sperm motility is sensitive to low concentrations of inhibitors of aquaporins such as $\mathrm{HgCl}_{2}$ (Cosson et al. 1999, Abascal et al. 2007). In turbot sperm, the effect of $\mathrm{HgCl}_{2}$, supposedly targeted to aquaporins, is chronologically double: first, inhibiting initiation of motility and secondly, inducing a 'twist' of the flagellum (Fig. 5). Both aquaporins and polycystin-like receptors genes are present in a fish genome, the zebra fish.

Putting all together these features with the knowledge about the osmotic signal, we propose to involve SACs and aquaporins in the signaling pathway of the fish sperm activation (Fig. 6). This paradigm proposes several steps:
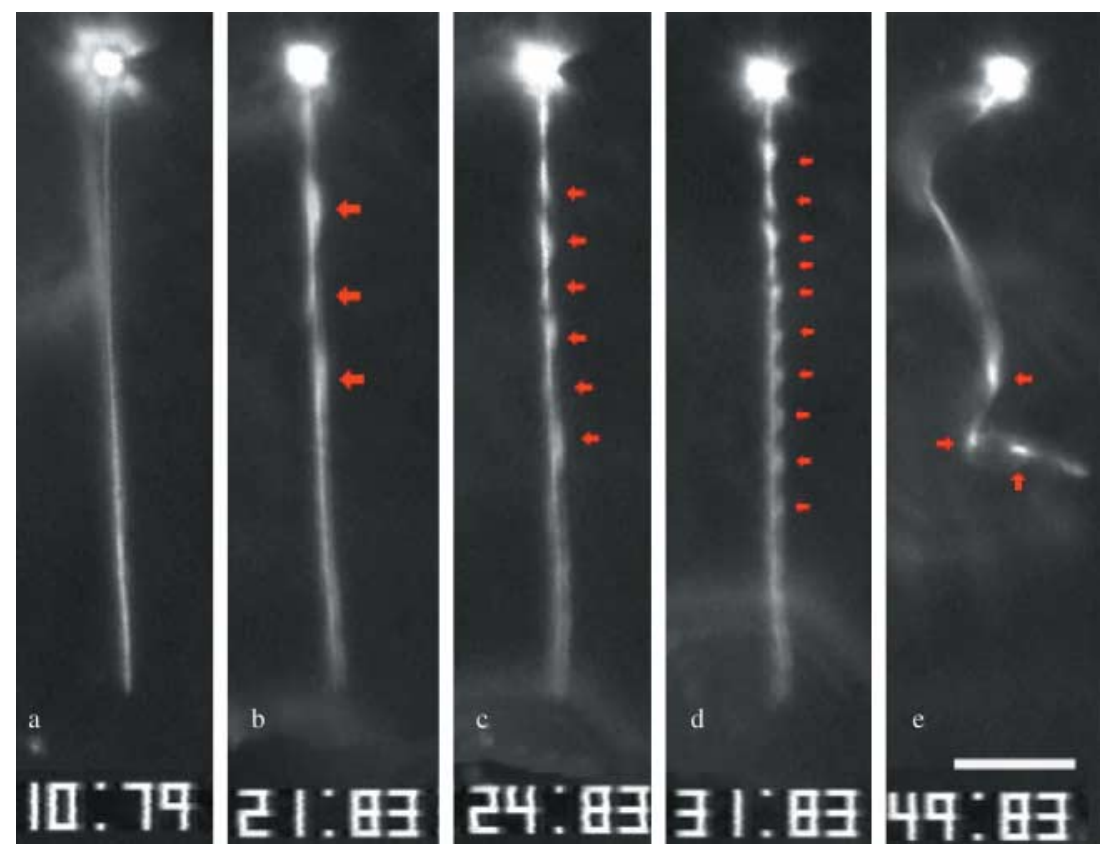

Figure 5 Effects of low concentrations of $\mathrm{HgCl}_{2}$ on sea bass spermatozoa. After the addition of spermatozoa to SW containing $200 \mu \mathrm{M} \mathrm{HgCl}_{2}$, flagella stop moving. After 3-4 min, they undergo an unusual curling process, mainly a twisting of the flagellum (as observed by dark field microscopy) taking several seconds to reach completion, then followed by partial unfolding. (a-e) Successive stages of this twisting shown by the red arrows, with timing in seconds at bottom. Scale bar: $10 \mu \mathrm{m}$. 


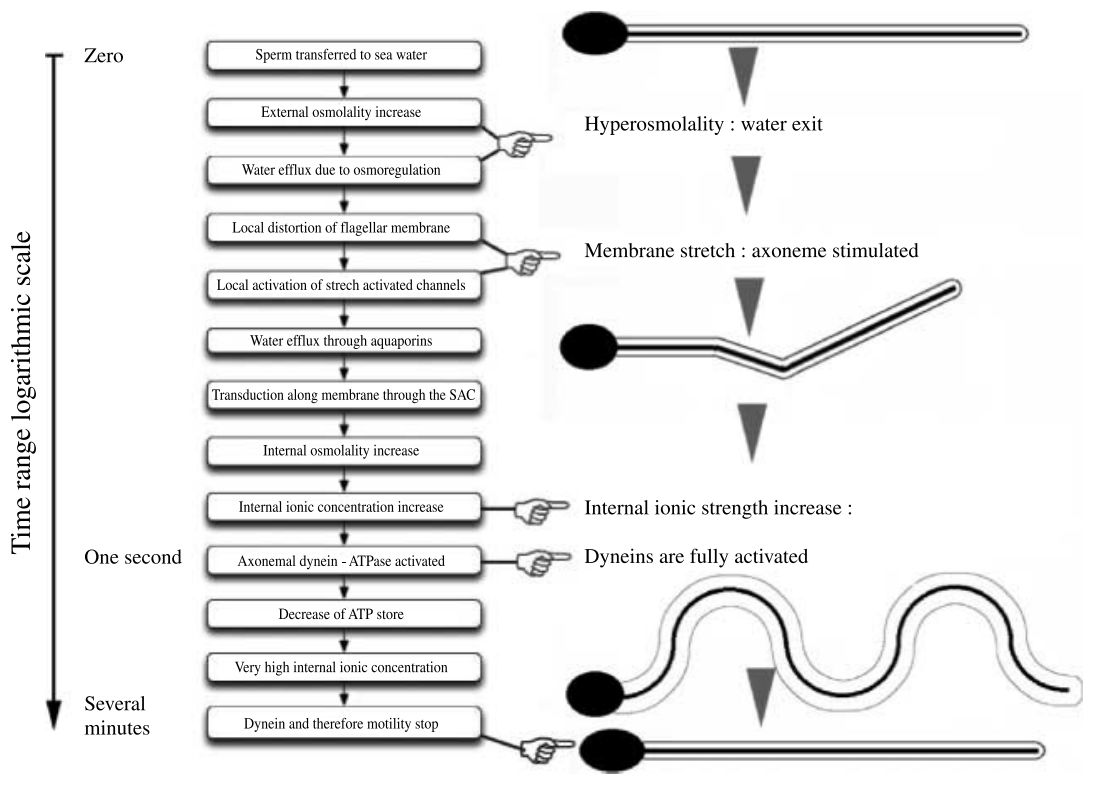

Figure 6 Activation process and signal transduction in marine spermatozoa: general schematic of the interacting processes occurring during the motility period of a turbot spermatozoon. Seawater is of much higher osmolality compared with SF: the osmolality jump induces an osmolality reaction at the sperm membrane level; water exits the sperm cell, a process accelerated by water pumps (aquaporins). As a consequence of water exit, internal ionic concentration increases and reaches optimal values for dynein motor activity. Beating of flagella is at maximal velocity but decreases with time because of two reasons: the ionic concentration becomes too high to sustain correct dynein activity and ATP concentration declines and becomes limiting for flagellar beating. After some period, flagellar activity stops because of these unfavorable conditions. the very first signal perceived by the membrane is osmotic; water exit would provoke a local membrane distortion or stretching. In this respect, the role of unusual creases shaped as fins (Cosson et al. 1999, Cosson 2007b) as discussed previously could be crucial not only in significantly increasing the membrane surface, this membrane 'excess' favoring water exchange, but also when distortions such as blebs appear on flagella exposed to extreme osmolalities (Perchec et al. 1996, Cosson et al. 2000). The SAC would respond immediately to this mechanical signal by increasing the local permeability, which would therefore allow ions such as $\mathrm{Ca}^{2+}$ or $\mathrm{K}^{+}$and/ or water to move rapidly in or out through channels or aquaporins. The triggering of an autocatalytic effect along flagellar membrane transmitted from place to place would explain why fish sperm activation proceeds in an extremely fast way (less than $20 \mathrm{~ms}$ according to our estimations). In fine, the local stretching of membranes would be the signal perceived by the axoneme because of the mechanosensitivity of this micromachine.

\section{Conclusions}

The present review primarily focuses on the mechanisms by which sperm motility can be triggered by SW as encountered by fishes with external fertilization.

The in vivo and in vitro observations of ionic strength control of axonemal activities are strengthened by observations of Billard (1978), Lahnsteiner \& Patzner (1998), and Groison et al. (AL Groison, M Suquet \& J Cosson, unpublished observations), which show that partly diluted SW supports longer sperm motility period than normal SW, as it leads to less harmful osmotical environment to sperm. Therefore, our in vitro observations combined with ATP measurements have lead us to a possible general schematic flow chart explaining how changes in the internal ionic concentration occurring in response to external osmolality could control fish sperm motility (Fig. 6). The response immediacy to the osmolality signal may be related to one major constraint endured by fish spermatozoa that are to obey a reproduction strategy in which a very brief period of reaction is needed to achieve the task. They exhibit a hypermotile behavior (high but brief BF) remarkably similar to the hyperactivated motility exhibited by mammalian spermatozoa in the vicinity of eggs before fertilization. The hypermotility of fish spermatozoa is demonstrated by a high velocity and a fast consumption of energy, which was stored during the spermatogenesis process. This strategy is probably dictated by another main constraint of many fishes, the short period of competence of the egg for fertilization in which the micropyle remains open only for 10-20 s after contact with SW.

As complementary information, some video files about fish sperm motility are available at http://biodev. obs-vlfr.fr/ cosson/fishsperm/fishsperm.html.

\section{Declaration of interest}

The authors declare that there is no conflict of interest that could be perceived as prejudicing the impartiality of the research reported.

\section{Funding}

The CNRS provided some funding to J C.

\section{Acknowledgements}

Our kindest thanks are addressed to Monik Cosson for her helpful perseverance in the editing process of the manuscript 
and to Sara Stewart for reviewing the English. The present review corresponds to an introductory lecture presented at The First International Workshop on Biology of Fish Sperm, August 29-31, 2007, Vodnany, Czech Republic.

\section{References}

Abascal FJ, Cosson J \& Fauvel C 2007 Characterization of sperm motility in European seabass. The effect of heavy metals and physicochemical variables on sperm motility. Journal of Fish Biology 70 509-522.

Alavi SMH \& Cosson J 2005 Sperm motility in fishes: (I) Effects of temperature and pH: a review. Cell Biology International 29 101-110.

Alavi SMH \& Cosson J 2006 Sperm motility in fishes: (II) Effects of ions and osmotic pressure: a review. Cell Biology International 30 1-14.

Alavi SMH, Cosson JJ, Coward K \& Rafiee G (Eds) 2008 Fish Spermatology. Oxford: Alpha Science International (ISBN 978-1-84265-369-2).

Amanze D \& Iyengar A 1990 The micropyle: a sperm guidance system in teleost fertilization. Development 109 495-500.

Atkinson DE 1968 The energy charge of the adenylate pool as regulatory parameter: interaction with feedback modifier. Biochemistry 7 4030-4034.

Baccetti B, Burrini AG, Dallai R \& Pallini V 1979 The dynein electrophoretic bands in axonemes lacking the inner or the outer arm. Journal of Cell Biology $80334-340$.

Billard R 1978 Changes in structure and fertilizing ability of marine and fresh water fish spermatozoa diluted in media of various salinities. Aquaculture 14 187-198.

Billard R \& Cosson M-P 1988 Sperm motility in rainbow trout Parasalmo mykiss: effect of $\mathrm{pH}$ and temperature. In Reproduction in Fish Basic and Applied Aspect in Endocrinology and Genetics, pp 161-167. Eds B Breton \& Y Zohar. Paris: INRA.

Billard R \& Cosson M-P 1990 The energetics of fish sperm motility. In Controls of Sperm Motility, Biological and Clinical Aspects, pp 153-173. Ed. C Gagnon. Boca Raton, Florida: CRC Press.

Billard R \& Cosson M-P 1992 Some problems related to the assessment of sperm motility in freshwater fish. Journal of Experimental Zoology $26 \mathbf{1}$ 122-131.

Billard R, Cosson J \& Crim LW 1993 Motility and survival of halibut sperm during short term storage. Aquatic Living Resources 6 67-75.

Billard R, Cosson J, Crim M \& Suquet M 1994 Physiology and quality of sperm in fish. European Aquaculture Society 19 203-218.

Billard R, Cosson J, Crim LW \& Suquet M 1995 Sperm physiology and quality. In Broodstock Management and Egg and Larval Quality, pp 25-52. Eds NR Bromage \& RJ Roberts. Cambridge, Massachusetts: Blackwell Sciences Ltd.

Bohmer M, Van Q, Weyand I, Hagen V, Beyermann M, Matsumoto M, Hoshi M, Hildebrand E \& Kaupp UB $2005 \mathrm{Ca}^{2+}$ spikes in the flagellum control chemotactic behavior of sperm. EMBO Journal 24 2741-2752.

Boitono S \& Omoto CK 1992 Trout sperm swimming patterns of role of intracellular $\mathrm{Ca}^{2+}$. Cell Motility and the Cytoskeleton 21 74-82.

Brokaw CJ 1966 Effects of increased viscosity on the movement of some invertebrate spermatozoa. Journal of Experimental Biology 45 113-139.

Brokaw CJ 1977 CO $_{2}$-inhibition of the amplitude of bending of Triton demembranated sea urchin sperm flagella. Journal of Experimental Biology 71 229-240.

Brokaw CJ 1991a Calcium sensors in sea urchin sperm flagella. Cell Motility and the Cytoskeleton 18 123-130.

Brokaw CJ $1991 b$ Microtubule sliding in swimming sperm flagella: direct and indirect measurements on sea urchin and tunicate spermatozoa. Journal of Cell Biology 124 1201-1215.

Brokaw CJ 2004 FlagsimX at http://www.cco.caltech.edu/ brokawc/ software.html

Brokaw CJ \& Simonick TF $1976 \mathrm{CO}_{2}$ regulation of the amplitude of flagellar bending. In Cell Motility, pp 933-940, book C, vol 3. Eds R Goldman, T Pollard \& J Rosenbaum. New York: Cold Spring Harbor Laboratory Press.

Carillo M, Zanuy S, Prat F, Cerda J, Ramos J, Mananos E \& Bromage R 1995 BroodstockManagement, ch 7, pp 138-168. Eds RN Bromage \& RJ Roberts. Oxford: Blackwell Science.

Chambeyron F \& Zohar Y 1990 A diluent for sperm cryoconservation of gilthead sea bream, Sparus aurata. Aquaculture 90 345-352.
Chauvaud L, Cosson J, Suquet M \& Billard R 1995 Sperm motility in turbot, Scophthalmus maximus, initiation of movement and changes with time of swimming characteristics. Environmental Biology of Fishes $\mathbf{4 3}$ 341-349.

Christen R, Gatti J-L \& Billard R 1987 Trout sperm motility: the transient movement of trout sperm is related to changes in the concentration of ATP following the activation of the flagellar movement. European Journal of Biochemistry 166 667-671.

Ciereszko A 2008 Chemical composition of seminal plasma and its physiological relationship with sperm motility, fertilizing capacity and cryopreservation in fish. In Fish Spermatology, pp 215-240. Eds SMH Alavi, JJ Cosson, K Coward \& G Rafiee. Oxford: Alpha Science International.

Cosson J 2004 The ionic and osmotic factors controlling motility of fish spermatozoa. Aquaculture International 12 69-85.

Cosson J 2007a Methods to analyse the movements of fish spermatozoa and their flagella. In Fish Spermatology, ch 2, pp 63-101. Eds SMH Alavi, JJ Cosson, K Coward \& G Rafiee. Oxford (UK): Alpha Science.

Cosson J 2007b The motility apparatus of fish spermatozoa. In Fish Spermatology, ch 9, pp 281-316. Eds SMH Alavi, JJ Cosson, K Coward \& G Rafiee. Oxford (UK): Alpha Science.

Cosson M-P \& Gagnon C 1988 Protease inhibitors and substrates block motility and microtubule sliding of sea urchin and carp spermatoza. Cell Motility and the Cytoskeleton 10 518-527.

Cosson M-P, Billard R, Gatti J-L \& Christen R 1985 Rapid and quantitative assessment of trout spermatozoa motility using stroboscopy. Aquaculture $4671-75$.

Cosson M-P, Cosson J \& Billard R 1991 Synchronous triggering of trout sperm is followed by an invariable set sequence parameters whatever the incubation medium. Cell Motility and the Cytoskeleton 20 55-68.

Cosson M-P, Cosson J, André F \& Billard R 1995a cAMP/ATP relationship in the activation of trout sperm motility: their interaction in membranedeprived models and in live spermatozoa. Cell Motility and the Cytoskeleton 31 159-176.

Cosson J, Linhart O \& Billard R 1995b Motility of Siberian Sturgeon (Acipenser baeri) spermatozoa. Sturgeon Quarterly 3 9-10.

Cosson J, Billard R, Cibert C, Dreanno C, Linhart O \& Suquet M 1997 Movements of fish sperm flagella studied by high speed videomicroscopy coupled to computer assisted image analysis. Polish Archives of Hydrobiology 44 103-113.

Cosson J, Dreanno C, Billard R, Suquet M \& Cibert C 1999 Regulation of axonemal wave parameters of fish spermatozoa by ionic factors. In The Male Gamete: from Basic Knowledge to Clinical Applications, pp 161-186. Ed. C Gagnon. Montréal, Canada: Cache River Press.

Cosson J, Linhart O, Mims S, Shelton W \& Rodina M 2000 Analysis of motility parameters from paddlefish (Polyodon spathula) and shovelnose sturgeon (Scaphirhynchus platorynchus) spermatozoa. Journal of Fish Biology 56 1348-1367.

Cosson J, Huitorel P \& Gagnon C 2003 How spermatozoa come to be confined to surfaces. Cell Motility and the Cytoskeleton 54 56-63.

Cosson J, Groison A-L, Suquet M \& Fauvel C 2008a Motility characteristics of spermatozoa in cod (Gadus morhua) and hake (Merluccius merluccius). Cybium [in press].

Cosson J, Groison A-L, Suquet M, Fauvel M, Dreanno C \& Billard R $2008 b$ Traits of sperm motility in marine fish: a review and new data. Journal of Applied Ichthyology [in press].

Coward K, Campos-Mendoza A, Larman MG, Hibbit O, McAndrew BJ, Bromage NR \& Parrington J 2003 Teleost fish spermatozoa contain a cytosolic protein factor that induces calcium release in sea urchin egg homogenates and triggers calcium oscillations when injected into mouse oocytes. Biochemical and Biophysical Research Communications 305 299-304.

Doi M, Hoshino T, Taki Y \& Ogasawara Y 1982 Activity of the sperm of the bluefin tuna Thunnus thynnus under fresh and preserved conditions. Bulletin of the Japanese Society of Scientific Fisheries 48 495-498.

Doumenge F 1999 L'aquaculture des thons rouges et son développement économique. Biologia Marina Mediterranea 6 107-148.

Dreanno C 1998 Régulation de la mobilité des spermatozoïdes de turbot (Psetta maxima) et de bar (Dicentrachus labrax) Etude du métabolisme énergétique, du contrôle ionique, de la morphologie et du pouvoir fécondant. PhD Thesis. University Rennes, France p 103. 
Dreanno C, Suquet M, Cosson J, Cibert C, Huignard H \& Billard R 1995 $\mathrm{CO}_{2}$ effects on flagella of native and demembranated turbot spermatozoa. In International Symposium on Reproductive Physiology of fish $\mathrm{p} 5$. the University of Texas at Austin, Austin TX.

Dreanno C, Suquet M, Quemener L, Cosson J, Fierville F, Normand Y \& Billard R 1997 Cryopreservation of Turbot (Scophthalmus maximus) sperm. Theriogenology 48 589-603.

Dreanno C, Suquet M, Desbruyeres E, Cosson J, Le Delliou H \& Billard R 1998 Effect of urine on semen quality in Turbot (Scophthalmus maximus). Aquaculture 169 247-262.

Dreanno C, Suquet M, Fauvel C, Le Coz JR, Dorange G, Quemener L \& Billard R 1999a The effect of ageing process on the quality of sea bass (Dicentrarchus labrax) semen. Journal of Applied Ichthyology 15 176-180.

Dreanno C, Cosson J, Suquet M, Dorange G, Fauvel C, Cibert C \& Billard R $1999 b$ Effects of osmolality, morphology and intracellular nucleotid content during the movement of sea bass (Dicentrarchus labrax) spermatozoa. Journal of Reproduction and Fertility 116 113-125.

Dreanno C, Seguin F, Cosson J, Suquet M \& Billard R 1999c Metabolism of turbot (Scophthalmus maximus) spermatozoa: relationship between motility, intracellular nucleotid content and mitochondrial respiration. Molecular Reproduction and Development 53 230-243.

Dreanno C, Cosson J, Suquet M, Nagahama Y \& Billard R 1999d Effect of ionic strength on the motility of turbot (Psetta maxima) spermatozoa. In Proceedings of the 6th International Symposium on the Reproductive Physiology of Fish Bergen p 256.

Dreanno C, Seguin F, Cosson J, Suquet M \& Billard R $2000 \mathrm{H}^{+}-\mathrm{NMR}$ and ${ }^{31} \mathrm{P}-$ NMR analysis of energy metabolism of quiescent and motile turbot ( $P$ setta maxima) spermatozoa. Journal of Experimental Zoology 286/5 513-522.

Ehrenbaum E 1905 Eier und Larven von Fischen des nordishen planktons, pp 1-216. Kiel u. Liepzig: Lipsius \& Tisher.

Fauvel C, Suquet M, Dreanno C, Zonno V \& Menu B 1998 Cryopreservation of sea bass (Dicentrarchus labrax L.) spermatozoa in experimental and production conditions. Aquatic Living Resources 11 387-394.

Fauvel C, Savoye O, Dreanno C, Cosson J \& Suquet M 1999 Characteristics of sperm of captive seabass (Dicentrarchus labrax L.) in relation to its fertilisation potential. Journal of Fish Biology 54 356-369.

Gibbons IR 1981 Cilia and flagella of eukaryotes. Journal of Cell Biology 91 $107 \mathrm{~s}-124 \mathrm{~s}$.

Gibbons BH \& Gibbons IR 1983 Certain organic anions improve the reactivated motility of sea urchin sperm flagella. Journal of Cell Biology 975 a.

Gibbons IR, Evans JA \& Gibbons BH 1982 Acetate anions stabilize the latency of dynein 1 ATPase and increase the velocity of tubule sliding in reactivated sperm flagella. Cell Motility 1 (Suppl.) 181-184.

Gibbons BH, Baccetti B \& Gibbons IR 1985 Motility of the $9+0$ flagellum of Anguilla sperm. Cell Motility 5 333-350.

Gosh RI 1985 Energeticzeskij obmen polovych kletok i embryonoy u ryb, pp 147. Kiev: Naukova Dumka.

Griffin FJ, Vines CA, Pillai MC, Yanagimachi R \& Cherr GN 1996 Sperm motility initiation factor is a minor component of the Pacific herring egg chorion. Development, Growth and Differentiation 38 193-202.

Groison A-L, Suquet M, Cosson J, Le Coz J-R, Jolivet A \& Garren F 2008 Sperm biological characteristics in European hake (Merluccius merluccius). Cybium [in press].

Guest WC, Avault JW \& Roussel JD 1976 Preservation of channel catfish sperm. Transactions of the American Fisheries Society 105 469-474.

Gunaratne HJ \& Vacquier VD 2006 Evidence for a secretary pathway $\mathrm{Ca}^{2+}$. ATPase in sea uechin spermatozoa. FEBS Letters 580 3900-3904.

Gwo JC 1995 Ultrastructural study of osmolality effect on spermatozoa of three marine teleosts. Tissue \& Cell 27 491-497.

Harper CV, Barrat CL \& Publicover SJ 2004 Stimulation of human spermatozoa with progesterone gradients to simulate approach to the oocyte. Journal of Biological Chemistry 279 46315-46325.

Hay DE 1985 Reproductive biology of Pacific Herring (Clupea harengus pallasi). Canadian Journal of Fisheries and Aquatic Sciences 42 (Suppl.) 111-126.

Ho HC \& Suarez SS 2003 Characterisation of the intracellular calcium store at the base of sperm flagellum that regulates hyperactivated motility. Biology of Reproduction 68 1590-1596.

Hwang PC \& Idler DR 1969 A study of major cations, osmotic pressure, and $\mathrm{pH}$ in seminal components of Atlantic salmon. Journal of the Fisheries Research Board of Canada 26 413-419.

Inaba K 2003 Molecular architecture of sperm flagella: molecules for motility and signaling. Zoological Science 20 1043-1056.
Inaba K, Dreano C \& Cosson J 2003 Control of sperm motility by $\mathrm{CO}_{2}$ and carbonic anhydrase in flatfish. Cell Motility and the Cytoskeleton 55 174-187.

Ingber DE 2006 Cellular mechanotransduction: putting all the pieces together again. FASEB Journal 20 811-827.

Iwamatsu T, Ishijima S \& Nakashima S 1993 Movement of spermatozoa and changes in micropyles during fertilization in medaka eggs. Journal of Experimental Zoology 266 57-64.

Kaupp UB, Hildebrand E \& Weyand I 2006 Sperm chemotaxis in marine invertebrates - molecules and mechanisms. Journal of Cellular Physiology 208 487-494.

Kime DE \& Tveiten H 2002 Unusual motility characteristics of sperm of the spotted wolffish. Journal of Fish Biology 61 1549-1559.

Kjorsvik E \& Holmefjord I 1995 Broodstock Management, pp 169-196. Eds NR Bromage \& RJ Roberts. Oxford: Blackwell Science.

Krasznai Z, Morisawa M, Krasznai ZT, Morisawa S, Inaba K, Bazsane ZK, Rubovszky B, Bodnar B, Borsos A \& Marian T 2003 Gadolinium, a mechano-sensitive channel blocker, inhibits osmosis-initiated motility of sea- and freshwater fish sperm, but does not affect human or ascidian sperm motility. Cell Motility and the Cytoskeleton 55 232-243.

Lahnsteiner F \& Patzner R 1998 Sperm motility in the marine teleosts Boops boops, Diplodus sargus, Mullus barbutus and Trachurus mediterraneus. Journal of Fish Biology 52 726-742.

Lahnsteiner F \& Patzner RA 2007 Sperm morphology and ultrastructure in fish. In Fish Spermatology, pp 1-62. Eds SMH Alavi, JJ Cosson, K Coward \& G Rafiee. Oxford (UK): Alpha Science.

Lechtreck KF \& Witman GB 2007 Chlamydomonas reinhardtii hydin is a central pair protein required for flagellar motility. Journal of Cell Biology 176 473-482.

LeDizet M \& Piperno G 1995 The light chain p28 associates with a subset of inner arm heavy chains in Chlamydomonas axonemes. Molecular Biology of the Cell 6 697-711.

Lee CS, Tamaru CD, Kelley A, Moriwake A \& Miyamoto GT 1992 The effect of salinity on the induction of spawning and fertilization in the stripped mullet, Mugil cephalus. Aquaculture 102 289-296.

Legendre M, Cosson J, Alavi SMH \& Linhart O 2008 Sperm motility activation in the euryhaline tilapia Sarotherodon melanotheron heudelotii (Dumeril, 1859) acclimatized to fresh, sea or hypersaline waters. Cybium [in press].

Lindemann CB \& Rickemenspoel R 1972 Sperm flagella: autonomous oscillations of the contractile system. Science 175 337-338.

Linhart O, Walford J, Sivaloganathan B \& Lam TJ 1999 Effects of osmolality and ions on the motility of stripped and testicular sperm of freshwaterand seawater-acclimated tilapia, Oreochromis mossambicus. Journal of Fish Biology 55 1344-1358.

Litvak MK \& Trippel EA 1998 Sperm motility patterns of Atlantic cod (Gadus morhua) in relation to salinity: effects of ovarian fluid and egg presence. Canadian Journal of Fisheries and Aquatic Sciences 55 1871-1877.

Miller TJ, Herra T \& Leggett WC 1995 An individual-based analysis of the variability og eggs and their newly hatched lavae of atlantic cod (Gadus morhua) on the Scotian Shelf. Canadian Journal of Fisheries and Aquatic Sciences 52 1083-1093.

Minamikawa S \& Morisawa M 1996 Acquisition, initiation and maintenance of sperm motility in the shark, Triakis scyllia. Comparative Biochemistry and Physiology 113A 387-392.

Morisawa M 1985 Initiation mechanism of sperm motility at spawning in teleost. Zoological Science 2 605-615.

Morisawa M 1994 Cell signalling mechanism for sperm motility. Zoological Science 11 647-662.

Morisawa S 1995 Fine structure of spermatozoa of the hagfish Eptatetrus burgeri (Agnatha). Biological Bulletin 189 6-12.

Morisawa M \& Suzuki K 1980 Osmolality and potassium ion: their role in initiation of sperm motility. Science 210 1145-1147.

Morita M, Takemura A \& Okuno M 2003 Requirement of $\mathrm{Ca}^{2+}$ on activation of sperm motility in euryhaline tilapia (Oreochromis mossambicus). Journal of Experimental Biology 206 913-921.

Morita M, Takemura A, Nakajima A \& Okuno M 2006 Microtubule sliding movement in tilapia sperm flagella axoneme is regulated by $\mathrm{Ca}^{2+} / \mathrm{cal}-$ modulin-dependent protein phosphorylation. Cell Motility and the Cytoskeleton 63 459-470.

Murua H \& Motos L 2006 Reproductive strategy and spawning of the European Hake Merluccius merluccius (L.) in the Bay of Biscay. Journal of Fish Biology 69 1288-1303. 
Mylonas CC, Bridges C, Gordin H, Belmonte Ríos A, García A, De la Gándara F, Fauvel C, Suquet M, Medina A, Papadaki M et al. 2007 Preparation and administration of gonadotropin-releasing hormone agoinst $(\mathrm{GnRHa})$ implants for the artificial control of reproductive maturation in captive-reared Atlantic bluefin tuna (Thunnus thynnus thynnus). Reviews in Fisheries Science 15 183-210.

Nauli SM, Alenghat FJ, Luo Y, Williams E \& Vasiliev P 2003 Polycystins 1 and 2 mediate mechanosensation in the primary cilium of kidney cells. Nature Genetics 33 129-137.

Oda S, Igarashi Y, Ohtake H, Sakai K, Shimizu N \& Morisawa M 1995 Sperm-activating proteins from unfertilized eggs of the Pacific Herring, Clupea pallasi. Development, Growth and Differentiation 37 257-261.

Oda S, Igarashi Y, Manaka K, Koibuchi N, Sakai-Sawada M, Sakai K, Morisawa M, Ohtake H \& Shimizu N 1998 Sperm-activating proteins obtained from the herring eggs are homologous to trypsin inhibitors and synthesized in follicle cells. Developmental Biology 204 55-63.

Pan J, Wang Q \& Snell WJ 2005 Cilium signaling and cilia related disorders. Laboratory Investigation 85 452-463.

Pavlov DA 1994 Fertilization in the wolffish, Anarhichas lupus: external or internal? Biol. Journal of Ichthyology/Voprosy Ikhtiologii (J. Ichthyol.; Vopr. Ikhtiol.) pp 664-670 Moscow State University Ed., Moscow, Russia.

Pavlov DA, Knudsen P, Emel'Yanova NG \& Moksness E 1997 Spermatozoon ultrastructure and sperm production in wolffish (Anarhichas lupus) a species with internal fertilization. Aquatic Living Resources 10 187-194.

Pazour GJ \& Rosenbaum JL 2002 Intraflagellar transport and ciliadependent diseases. Trends in Cell Biology 12 551-555.

Pazour GL, Agrin N, Leszyk J \& Witman GB 2005 Proteomic analysis of a eukariotic cilium. Journal of Cell Biology 170 103-113.

Perchec G, Cosson J, André F \& Billard R 1993 La mobilité des spermatozoïdes de truite (Oncorhynchus mykiss) et de carpe (Cyprinus carpio). Journal of Applied Ichthyology 9 129-149.

Perchec G, Jeulin C, Cosson J, André F \& Billard R 1995a Relationship between sperm ATP content and motility of carp spermatozoza. Journal of Cell Science 108 747-753.

Perchec G, Cosson J, André F \& Billard R 1995b Degradation of the quality of carp sperm by urine contamination during stripping. Aquaculture 129135.

Perchec G, Cosson M-P, Cosson J, Jeulin C \& Billard R 1996 Morphological and kinetic sperm changes of carp (Cyprinus carpio) spermatozoa after initiation of motility in distilled water. Cell Motility and the Cytoskeleton 35 113-120.

Perchec-Poupard G, Gatti J-L, Cosson J, Jeulin C, Fierville F \& Billard R 1997 Effects of extracellular environment on the osmotic signal transduction involved in activation of motility of carp spermatozoa. Journal of Reproduction and Fertility 110 315-327.

Perchec-Poupard G, Paxion C, Cosson J, Jeulin C, Fierville F \& Billard R 1998 Initiation of carp spermatozoa motility and early ATP reduction after milt contamination by urine. Aquaculture 160 317-328.

Piperno G \& Ramanis Z 1991 The proximal portion of Chlamydomonas flagella contains a distinct set of inner dynein arms. Journal of Cell Biology 112 701-709.

Potts WTW \& Eddy FB 1973 The permeation to water of the eggs of certain marines teleosts. Journal of Comparative Physiology 82 305-315.

Prescott DM 1955 Effect of activation on the water permeability of salmon eggs. Journal of Cellular and Comparative Physiology 45 1-12.

Rakitin A, Fergusson MM \& Trippel EA 2001 Male reproductive success and body size in cod. Marine Biology 138 1077-1085.

Redondo-Müller C, Cosson M-P, Cosson J \& Billard R 1991 In vitro maturation of the potential for movement of carp spermatozoa. Molecular Reproduction and Development 29 259-270.

Robitaille PM, Munfort K \& Brown G $1987^{31}$ P nuclear magnetic resonance study of trout spermatozoa at rest, after motility and during short-term storage. Biochemistry and Cell Biology 65 474-485.

Saudrais C 1996 La créatine kinase du spermatozoïde de truite arc en ciel (Oncorynchus mykiss): aspects biochimiques et moléculaires, localisation dans le gamète et participation à son métabolisme énergétique. PhD thesis. University of Rennes, France pp 1-154.

Saudrais C, Fierville F, Loir M, Le Rumeur E, Cibert C \& Cosson J 1998 The use of phosphocreatine plus ADP as energy source for motility of membrane-deprived trout spermatozoa. Cell Motility and the Cytoskeleton 41 91-106.
Shiba K, Marian T, Krasznai Z, Baba SA, Morisawa M \& Yoshida M 2006 $\mathrm{Na}^{+} / \mathrm{Ca}^{2+}$ exchanger modulates the flagellar wave pattern for the regulation of motility activation and chemotaxis in the ascidian spermatozoa. Cell Motility and the Cytoskeleton 63 623-632.

Shuyang H, Jenkins-Keeran K \& Curry Woods L 2004 Activation of sperm motility in striped bass via a cAMP-independent pathway. Theriogenology 611 487-1498.

Stacey NE \& Hourston AS 1982 Spawning and feeding behavior of captive Pacific Herring, Clupea harengus pallasi. Canadian Journal of Fisheries and Aquatic Sciences 39 489-498.

Stein WD 2002 Cell volume homeostasis: ionic and nonionic mechanisms. International Review of Cytology 215 231-258.

Stoss J 1983 Fish gamete preservation and spermatozoan physiology. In Fish Physiology, pp 305-350. Eds WS Hoar, DJ Randall \& EM Donaldson. New York, London: Academic Press.

Suquet M, Billard R, Cosson J, Chauvaud L, Dorange G \& Fauvel C 1994 Sperm features in turbot (Scophthalmus maximus): a comparison with other fresh water and marine fish species. Aquatic Living Resources 7 283-294.

Suquet M, Dreanno C, Dorange G, Normant Y, Quemener L, Gaignon JL \& Billard R 1997 The ageing phenomenon of turbot (Scophthalmus maximus) sperm: effects on morphology, spermatozoa motility and concentration, ATP content, fertilization and storage capacities. Journal of Fish Biology 52 31-41.

Takai H \& Morisawa M 1995 Change in intracellular $\mathrm{K}^{+}$concentration caused by external osmolality change regulates sperm motility of marine and freshwater teleosts. Journal of Cell Science 108 1175-1181.

Tanaka H \& Oka Y 2005 Chaotropic ions and multivalent ions activate sperm in the viviparous fish guppy Poecilia reticulata. Biochemica et Biophysica Acta 1724 173-180.

Tombes RM, Brokaw CJ \& Shapiro BM 1987 Creatine kinase-dependent energy transport in sea urchin spermatozoa: flagellar wave attenuation and theoretical analysis of high energy phosphate diffusion. Biophysical Journal 52 75-86.

Trippel EA \& Morgan MJ 1994 Sperm longevity in atlantic cod (Gadus morhua). Copeia 4 1025-1029.

Trippel EA \& Neilson JD 1992 Fertility and sperm quality of virgin and repeatspawning Atlantic cod (Gadus morhua) and associated hatching success. Canadian Journal of Fisheries and Aquatic Sciences 49 2118-2127.

Turner A 1993 Teleost mating behaviour. In Behaviour of Teleost Fishes, pp 307-331. Ed. TJ Pitcher. New York (USA): Chapman and Hall.

Vandorpe DH, Small DL, Dabrowski AR \& Morris CE 1994 FMRamide and membrane strech as activators of the Aplysia S-channel. Biophysical Journal 66 46-58.

Vermeirssen ELM, Mazorra de Quero C, Shields RJ, Norberg B, Kime DE \& Scott AP 2004 Fertility and motility of sperm from Atlantic halibut (Hippoglossus hippoglossus) in relation to dose and timing of gonadotrophin-relasing hormone agonist implant. Aquaculture $\mathbf{2 3 0}$ 547-567.

Villani P \& Catena C 1991 Crioconservazione di gameti maschili di spigola (Dicentrarchus labrax L.): soluzione e metodologie. Rivista Italiano di Aquacoltura 26 217-226.

Vines CA, Yoshida K, Griffin FJ, Murali C, Pillai MC, Morisawa M, Yanagimachi R \& Cherr GN 2002 Motility initiation in herring sperm is regulated by reverse sodium-calcium exchange. PNAS 99 2026-2031.

Vizziano D, Legac F \& Fostier A 1995 Synthesis and regulation of $17-\alpha-$ hydroxy-20- $\beta$-dihydroprogesterone in immature males of Oncorhynchus mykiss. Fish Physiology and Biochemistry 14 289-299.

Weisel GF 1948 Relation of salinity to the activity of the spermatozoa of Gillichthys, a marine teleost. Physiological Zoology 21 40-48.

Westin L \& Nissling A 1991 Effects of salinity on spermatozoa motility, percentage of fertilised eggs and egg development of Baltic cod (Gadus morhua) and implications for cod stock fluctuations in the Baltic. Marine Biology 108 5-9.

Wooley DM 1997 Studies on the eel sperm flagellum 1. The structure of the inner dynein arm complex. Journal of Cell Science 110 85-94.

Wooley DM 1998 Studies on the eel sperm flagellum. 2. The kinematic of normal motility. Cell Motility and the Cytoskeleton 39 233-245.

Yanagimachi R 1957 Studies of fertilization in Clupea pallasi. Parts 1-III. Zoological Magazine 66 218-233. 
Yanagimachi R, Cherr GN, Muralidharan C, Pillai MC \& Baldwin JD 1992 Factors controlling sperm entry into the micropyles of Salmonid and Herring eggs. Development, Growth and Differentiation 34 447-461.

Yang XC \& Sachs F 1993 Mechanically sensitive, non-selective cation channels. EXS 66 79-92.

Yang P, Diener DR, Rosenbaum JL \& Sale WS 2001 Localisation of calmodulin and dynein light chain LC8 in flagellar radial spokes. Journal of Cell Biology 153 1315-1326.

Yoshida K, Inaba K, Ohtake H \& Morisawa M 1999 Purification and characterisation of prolyl endopeptidase from the Pacific herring, Clupea pallasi, and its role in the activation of sperm motility. Development, Growth and Differentiation 41 217-225.
Zilli L, Schiavone R, Zonno V, Storelli C \& Vilella S 2004 Adenosine triphosphate concentration and beta-D-glucuronidase activity as indicators of sea bass semen quality. Biology of Reproduction 70 1679-1684.

Received 20 November 2007

First decision 1 February 2008

Revised manuscript received 30 April 2008

Accepted 2 June 2008 